\title{
PUBLIC HEALTH AND POPULATION HEALTH: UNDERSTANDING HEALTH AND DISEASE
}

\section{LEARNING OBJECTIVES}

- Distinguish and compare the terms public health and population health

- Discuss the great public health achievements of the 20th century that increased life expectancy by 25 years

- Compare and contrast the leading causes of death in the United States and globally

- Discuss the global burden of disease at a time when mortality is declining and disability is rising

- Describe the importance of developing the skill of "population health thinking"

\section{OVERVIEW: PUBLIC HEALTH, POPULATION HEALTH, AND POPULATION HEALTH SCIENCE: KEY DISTINCTIONS}

Humans have long recognized the need to develop systems that can create healthy populations. This has led to roots of organized public health that extend back millennia. ${ }^{1}$ Roman aqueducts were built, in part, to accommodate the need of growing cities to have clean water that was not contaminated by urban effluent. Jump forward a few centuries, and modern public health as we know it emerged principally from Western European countries, particularly England, France, and Germany, in the mid-19th century. Spurred by industrialization and the need to create healthier cities, the first formal health departments were established, and organized public health soon became one of the most important advances in human history leading to a period of unprecedented increase in life span worldwide, with average life expectancy jumping from around 40 years in the mid-1800s to around 80 years in most high-income countries in the present day.

It is this legacy that anyone starting on a journey in public health builds upon. This chapter aims to give the reader the foundations that can create a path for a lifetime of study or work in public health. To set those foundations, we first (a) explain core terms that underlie what we cover in this book, (b) describe the earliest origins of public health as a concern over the millennia, (c) explore the historical evolution of public health science and practice in the United States, (d) enumerate the major public health achievements in the United States over the 20th century and more recently, (e) differentiate what it means to be healthy or to experience disease, (f) rank the leading causes of death and identify the most common forms of illness in the United States and globally that contribute to the global burden of disease, (g) explain the current organization of public health 
practice in the United States, (h) discuss the organization of public health globally with particular reference to the World Health Organization (WHO), and (i) provide a case study on population health thinking.

\section{POPULATION}

Public health is about populations, which requires that students actively think in terms of population health. Although population thinking is essential to public health science and practice, it is not an intuitive way of thinking. More often than not, our attention gravitates to a particular important individual, the person at the center of our "selfies." Population thinking necessarily moves us beyond ourselves to considering more than one individual. This certainly includes other individuals with whom we are closely connected and groups of individuals of which we are a part. Extending beyond our own social networks, such thinking has us consider many other groups in which we have no obvious membership or deep connection.

So, what is a population? Two properties are necessary to describe a population. ${ }^{2}$ First, a population requires more than one individual. Second, these individuals share one or more common characteristics.

\section{Two properties are necessary to describe a population:}

First, a population requires more than one individual.

Second, these individuals share one or more common characteristics.

So really, a population of interest could be as small as two persons or as encompassing as the citizenry of the entire planet. By way of example, at the expansive extreme of this continuum, one century ago while the world was suffering the ravages of World War I, pandemic influenza was circling the globe. ${ }^{3}$ The death toll from this deadliest-ever outbreak was estimated in the range of 50 to 100 million at a time when the global population was about 1.5 billion people and everyone was susceptible.

Quite often, we define a population as people in a particular place. Often, places have discernible geopolitical boundaries; we talk about the population of a city, region, or country. A population may be further defined by a set of commonalities, one or more characteristics shared by members of the population. For example, we may have a population of employees in a particular workplace, or a population of people who have common hobbies or experiences. Either way, the study of public health rests on understanding the 
population we are concerned with so that we can improve the health of that population. Now, with a population lens in mind, we can start thinking about health.

\section{HEALTH}

What do we mean by health? The classic definition comes from the Constitution of the WHO, defining health as a state of complete physical, mental, and social well-being and not merely the absence of disease or infirmity. ${ }^{4}$ Through this definition, dating from 1948, the WHO Constitution described the enjoyment of the highest attainable standard of health as a fundamental right of every human being. Further, the WHO indicated that this is a right that should be accorded to all world citizens irrespective of race, economic or social condition, religion, or political belief. The WHO also noted that achieving health for all peoples is fundamental to the attainment of peace and security. To this day, the WHO Constitution continues to read like an enlightened call to arms seven decades after it was written. Importantly, this conception of health makes it clear that health is not just about the absence of disease. That means we are not interested only in giving people medicines to make them healthy after they get sick. Rather, we want to keep people healthy to begin with so that they can go about their business, living their lives. In this way of thinking, health is not an end-it is a means. It is a human right, one we should all have, so that we can choose to live our life as we wish to live it.

\section{PUBLIC HEALTH AND POPULATION HEALTH SCIENCE}

Now, with this in mind, what do we mean by public health?

There are many definitions of public health that we can lean on. The Centers for Disease Control and Prevention (CDC) Foundation notes that public health is the science of protecting and improving the health of families and communities through the promotion of healthy lifestyles, research for disease and injury prevention, and detection and control of infectious diseases. ${ }^{5}$

The American Public Health Association (APHA), the primary membership organization for public health professionals in the United States, considers the role of public health as being to promote and protect the health of people and the communities where they live, learn, work, and play. ${ }^{6}$

These definitions have not changed much over time. In 1920, Dr. Charles-Edward Amory Winslow, who established the Department of Public Health inside the Yale School of Medicine, described public health as the science and art of preventing disease, prolonging life, and promoting health through the organized efforts and informed choices of society, organizations, public and private, communities, and individuals. ${ }^{7}$

The common theme in all these definitions is that public health is about collective effort, work done by groups of us, aiming to create the conditions that can keep us all healthy. This definition informs how we approach this book. Importantly, we consider public health as being grounded in the science of population health. Population health science is the study of the conditions that shape distributions of health within and across populations, and the mechanisms through which these conditions manifest as the health of individuals. ${ }^{2}$ Population health science then provides us with the science and tells us what we need to know to understand what it is that causes health, so that then, in public health, we can intervene to make populations better.

Population health science provides us with the science and tells us what we need to know to understand what it is that causes health, so that then, in public health, we can intervene to make populations better. 
Therefore, this book is about the public's health and the practice of population health science. Throughout this book, we aim to explore how population health is produced, and what it is that public health does, or can do, to make populations healthier.

\section{THE HISTORY OF PUBLIC HEALTH}

\section{THE EARLY DAYS OF PUBLIC HEALTH}

Human habitation on this planet did not start out with populations as we think of them today. Human societies of Homo erectus, dating from 1.8 million years ago, and Homo sapiens, dating from 200,000 years ago, employed hunting and gathering as their predominant subsistence strategies. The survival of early humans depended on mobility in search of water and sustenance. At the most basic level, a primary indicator of health was staying alive. The average life expectancy was just over 20 years. Pockets of early humans regularly died out.

Our nomadic forebears established the baseline for what constitutes health today. Our human physiology developed and functioned optimally for this hunter-gatherer lifestyle.

Health and public health today are strongly shaped by how our primeval physiologies interact with our present-day lifestyles.

Health and public health today are strongly shaped by how our primeval physiologies interact with our present-day lifestyles.

The subsistence tasks of hunter-gatherer life were all-consuming. One of the initial economies that came from the clustering of humans into small bands was the development of the technology of the hunt. Even with the sporadic successful hunt, the bulk of the human diet still consisted of naturally-occurring foods including fruits, berries, nuts, seeds, tubers, and primitive grains. Humans remained nomadic, propelled by the imperative to seek and find available food and fresh water sources in their environment.

The hunter-gatherer diet was rich in foods of plant origin, high in fiber, and low in fat, saturated fat, sodium, and calories. Daily, periodically-strenuous physical activity was a mainstay of all subsistence activities. Hunter-gatherers needed to live close to sources of clean water, generally the same sources on which their plant-based diet depended. The constant mobility that defined hunter-gatherer life minimized the need to develop systems for sanitation. Although parasitic and communicable infectious diseases posed major threats to the health and longevity of hunter-gatherers, cardiovascular diseases and colon and lung cancers were virtually unknown.

Only in recent millennia (the most recent 7,000-8,000 years) have humans shifted toward settling in place and forming agriculture-based communities. For this to take place, it required the development of staple grains, like the fertile bread wheat, and the refinement of skills for cultivating and harvesting crops. The upside was the relative stability of the groups, now putting down roots and remaining in one locale. This was balanced against the downside that reliance on one primary grain led to widespread nutritional deficiencies and starvation following poor growing seasons. This was the epoch when populations, and by extension, population health, became meaningful.

The impetus for public health comes from humans living together in populations. As populations form and settle, two of the most basic survival concerns are ensuring a safe water supply and disposing of wastes; these remain central to public health today. The act of populating and residing in an area, and the ability to sustain that population, requires that water be 
brought in and wastes be shipped out, or otherwise neutralized. This requires organizationcollective action to promote health, or, in other words, public health. The construction of conduits for bringing water to human settlements dates back thousands of years. Excavations in the Indus Valley and the Punjab reveal primitive bathrooms, drains, and covered sewers. ${ }^{1}$ A hemisphere away, the Incas constructed elaborate baths and sewage systems.

In the middle ages, as European cities grew, several outbreaks of bubonic plague, caused by Yersinia pestis, illustrated the challenges occasioned by city living not accompanied by public health efforts to ensure health. ${ }^{8}$ Yersinia pestis resides in the intestines of fleas whose bites transmit the bacterium to rats. Rat populations thrived in the cities, harboring the disease and ensuring the survival of the bacterium. Incidentally, fleas also fed on humans, infecting them as they ingested a blood meal. Once an individual was infected, the bacteria replicated in the lymph nodes and spread to other tissues, producing a severe febrile illness with delirium and headache. Sixty percent of infected individuals died. Originating in Asia, bubonic plague epidemics surged throughout the entirety of Europe from the mid-1300s through the late 1700s.

Two public health tools emerged from the plague years in Europe in the middle ages to help cope with these epidemics: quarantine and isolation. As the scourge of bubonic plague, the Black Death, was ransacking Europe, quarantine measures were imposed on ships, passengers, and their cargo that had been potentially exposed to the disease. ${ }^{8}$ Ships were forced to anchor off port for a period of 40 days (the origin of the term, quarantine) to ensure that the disease was not on board, or had run its course. The parallel process for restricting entry and movement of possibly-infected persons traveling over land was the erection of a cordon sanitaire. This was a physical barrier that could not be crossed without permission. The use of this practice continued up to the early 20th century.

Fast forward to the mid-1800s and we come to mid-19th century London, where Edwin Chadwick advocated for improving living conditions in order to improve health. Chadwick argued, correctly, that improved health would improve productive output and reduce social costs. The tie-in to public health was his proposal to improve systems for providing clean water and to remove wastes and toxic substances. In this manner, the emerging field of public health found acceptability because it aligned with the economic priorities of the government. Public health actions to improve living conditions contributed to advancing life expectancy. Average life expectancy had hovered around 35 to 40 years throughout the 1700 s and the first half of the 1800s in England and Wales (Figure 1.1). The latter half of the 1800 s saw a gain of almost 10 years in life expectancy.

One of the most practical aspects of this movement was the passage of the Public Health Act of $1848 .^{9}$ The act created and operationalized the General Board of Health in London. In turn, the board directed the creation of local health boards that were charged with remedying environmental hazards to health in their localities. This set the model for much of what is modern public health practice to this day.

\section{THE EVOLUTION OF PUBLIC HEALTH IN THE UNITED STATES}

Several events that are relevant to public health in the United States date back to the late 1700s when Congress established the U.S. Marine Hospital Service (MHS) to deal with the health problems of sick and disabled seamen. MHS created a network of hospitals in port cities to provide care for seamen, who were regarded as a critical asset for the new nation. MHS was the predecessor of the U.S. Public Health Service (USPHS). The city of Boston played a central role as the site of the first marine hospital, and the city created the first board of health and the first health department in the United States. None other than the legendary Bostonian, Paul Revere, was the nation's first health officer.

It was a Massachusetts legislator, Lemuel Shattuck, who developed the first system for recording vital statistics-births, deaths, and marriages_-in the United States, one that 


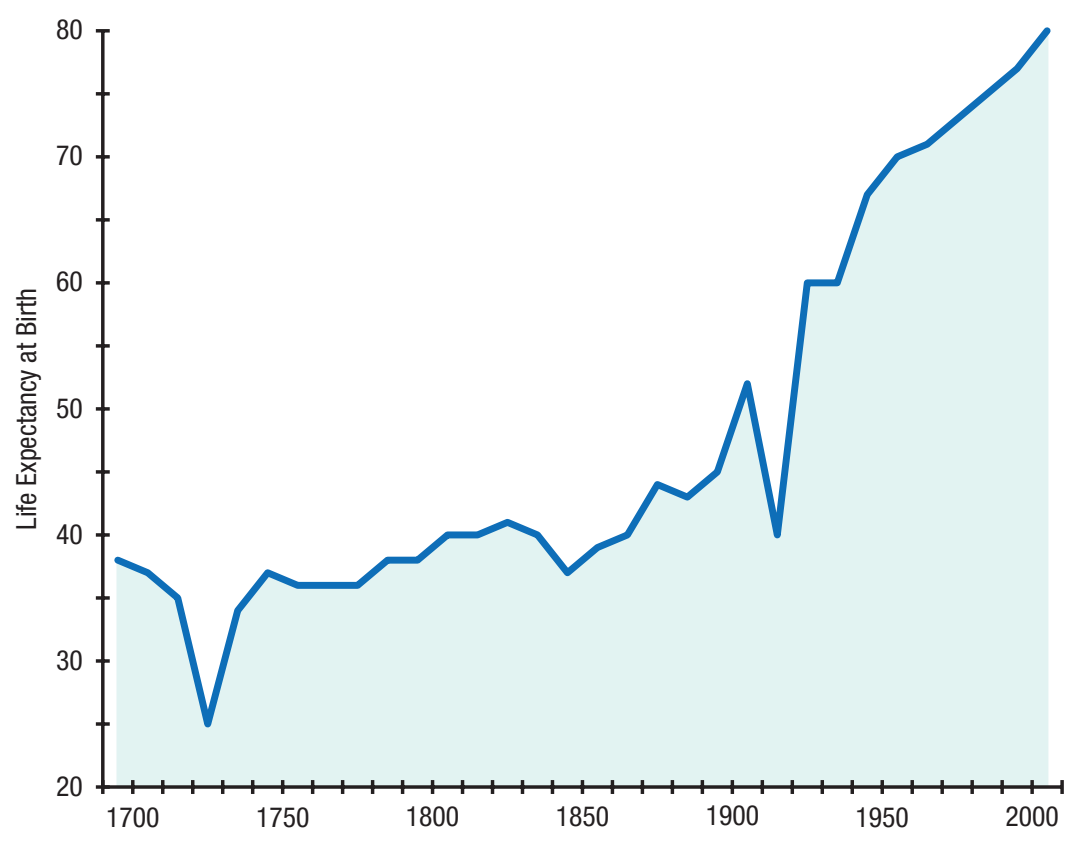

FIGURE 1.1 Life expectancy at birth in England and Wales, 1700-2005.

Source: Data from Roser M. (2019). Life Expectancy. Retrieved from: https://ourworldindata.org/life-expectancy

became an example for emulation by other states. Shattuck's contributions were substantial. He cross-tabulated mortality data by age, sex, occupation, socioeconomic level, and location. Further, he extended the use of health data to the recording of immunizations, smoking status, and alcohol abuse. Shattuck was also the architect of a public health survey for use throughout Massachusetts that was published in the New England Journal of Medicine, along with a consolidated set of 50 recommendations.

The 20th century was the era when the science and practice of public health truly came into its own in the United States. Key events in the timeline include the official naming of the USPHS in 1912. The USPHS was charged with investigating a range of human diseases. Prominent concerns at that time were tuberculosis, malaria, and leprosy. Within the purview of the USPHS were such mainstays of public health as sanitation, water supplies, and sewage disposal. National disease reporting was initiated in 1925. As one safeguard for the nation's health, legislation passed in 1938 created the Food and Drug Administration (FDA).

On the academic side, the first U.S. school of public health was founded in 1916 at Johns Hopkins University. Some of the earliest insights from population health scholarship that informed public health were studies that elucidated the causal relationship between cigarette smoking and rising lung cancer rates, published by Doll and Hill in 1948. In the same year, the Framingham Heart Study was launched. This research continues 70 years later as one of the most consequential studies that connects a series of lifestyle risk factors to the onset, progression, and mortality associated with cardiovascular and other noncommunicable diseases (NCDs).

In 1953, President Eisenhower created the U.S. Department of Health, Education, and Welfare. The year 1970 expanded the breadth of the public health agenda, marking the inception of both the Occupational Safety and Health Administration (OSHA) and the Environmental Protection Agency (EPA). In 1979, reorganization of the executive branch separated health and education into separate departments. Public health functions resided within the renamed and reorganized U.S. Department of Health and Human Services (HHS). 


\section{THE EVOLUTION OF ACADEMIC SCHOOLS OF PUBLIC HEALTH IN THE UNITED STATES}

\section{THE EARLY ORIGINS OF ACADEMIC PUBLIC HEALTH}

Academic schools of public health date back to the time of the Great Influenza. ${ }^{3,10}$ Years of planning went into the creation of health education that was distinct from the traditional medical school curriculum. In 1916, just prior to the onset of the global influenza pandemic, the Johns Hopkins University School of Hygiene and Public Health became the first school of public health, endowed by the Rockefeller Foundation. Early schools of public health were well-supported private institutions that were selectively populated by professionals with medical degrees. Not surprisingly, the education focused on infectious diseases. In the early decades, the prioritized enrollment of physicians, coupled with the failure to include field training, did not succeed in producing a cadre of graduates who could assume roles as public health officers and sanitarians.

Impetus for expanding public health education was provided by the Social Security Act of 1935. The act increased funding for the USPHS and upgraded qualifications for federally-funded health personnel that translated, in most states, into a requirement of at least 1 year of graduate education. This increase in public health positions created demand for public health credentials that triggered state universities to open new schools. By 1936, graduate public health training was offered in 10 institutions: Johns Hopkins, Harvard, Columbia, Michigan, University of California at Berkeley, Massachusetts Institute of Technology, Minnesota, Pennsylvania, Wayne State, and Yale. During the 1930s, there was a proliferation of 1-year graduates who received a Master of Public Health (MPH) degree, with its strong emphasis on applied field training.

The expansion of public health training continued during the Second World War to prepare physicians, nurses, and sanitarians with skills to deal with tropical and parasitic diseases, sexually transmitted infections, and sanitation in the theaters of war. Training also was provided to impart industrial hygiene skills to ensure the health of workers in the domestic industries that supported the war effort. This boom in public health training was accompanied by the formation of the Association of Schools of Public Health (ASPH) in 1941 and the establishment of the Council on Education for Public Health (CEPH) of the APHA, adding rigor and standardization to public health curricula.

\section{POST-WORLD WAR II AND ACADEMIC PUBLIC HEALTH TODAY}

The focus on preparing public health practitioners through applied courses and fieldwork took a downturn after the war when university funding for public health faculty shifted toward an imperative for these professionals to compete for research grant support. Foundation support for public health education dwindled. Schools of public health found themselves at a disadvantage when competing with medical schools for National Institutes of Health (NIH) and other research support. Community-focused field training educational programs vanished. Nationwide, enrollment in graduate public health education decreased by half by the mid-1950s.

Later that decade, an emergency infusion of federal funding partially revived public health education. In 1958, the First National Conference on Public Health Training was held. The introduction of major national social programs of the 1960s-Medicare and Medicaid-once again increased the demand for public health education, this time focusing on healthcare delivery. The 1960s and 1970s saw a revitalization of graduate public health training as schools of public health received direct funding for training along with 
enhanced ability to compete for research grants. However, just as the number of graduate public health degrees awarded annually was approaching 5,000, President Nixon attempted to eliminate all federal funding for schools of public health and for research training grants in 1973.

Fortunately, funding was not terminated and in 1976, the Milbank Memorial Fund published a detailed public health roadmap report, Higher Education for Public Health, that proposed a three-tiered structure for public health education. ${ }^{11}$ This included the preparation of public health leaders; created specialist public health training for nurses, health educators, and environmental health professionals; and added an undergraduate training component to graduate entry-level personnel. The report defined core disciplines within public health and recommended a role for the schools as regional resources to educational institutions in the area of public health research. It also highlighted engagement of schools in local community health services and renewed emphasis on public health practice.

There are currently 66 schools of public health and 121 programs in public health that are accredited by the Council on Education for Public Health. These programs are distributed across 47 states and eight countries.

Today, the public health ecosystem includes schools of public health, official governmental bodies charged with promoting health, nongovernmental organizations (NGOs), and a range of international bodies, all aspiring to create the conditions for states of complete physical and mental well-being for as many people as possible.

\section{WHAT ARE THE MAJOR PUBLIC HEALTH ACHIEVEMENTS OVER THE 2OTH CENTURY AND MORE RECENTLY IN THE UNITED STATES?}

Public health has transformed healthy life and catapulted life expectancy forward within the past 120 years. In fact, during the 20th century, life expectancy in the United States increased by 30 years. The CDC credits 25 years of this quantum gain in life expectancy to 10 great public health achievements during the 20th century, 1900-1999. ${ }^{12}$ Here is the roster in alphabetical order:

Ten Great Public Health Achievements-United States, 1900-1999:12

- Control of infectious diseases

- Family planning

- Fluoridation of drinking water

- Decline in deaths from coronary heart disease and stroke

- Healthier mothers and babies

- Motor vehicle safety

- Recognition of tobacco use as a health hazard

- Safer and healthier foods

- Safer workplaces

- Vaccination

We select a subset of these achievements for further discussion.

\section{VACCINATION AND CONTROL OF INFECTIOUS DISEASES - TWO CLOSELY INTERRELATED ACHIEVEMENTS}

Vaccination was a major contributor to the control of infectious diseases in past decades. Smallpox was declared eradicated in 1979. Smallpox, a disease that only produced illness 
in humans, transformed the course of history over centuries. European explorers unknowingly introduced smallpox to the Americas, decimating populations of First Nations peoples who were immunologically naïve to the disease. ${ }^{13}$ Poliomyelitis was banished from the Western Hemisphere during the 20th century. The spread of measles, diphtheria, rubella, and tetanus was well controlled through childhood vaccination.

Beyond vaccine-preventable diseases, water purification and improved sanitation-fundamental pillars of public health-successfully decreased the disease burden of major killers like typhoid and cholera. The introduction of antimicrobial therapies diminished the spread of tuberculosis and some sexually transmitted infections.

\section{HEALTHIER MOTHERS AND BABIES, FAMILY PLANNING, AND FOOD SAFETY}

The health and survival of mothers and their children benefitted from improved hygiene and better nutrition. Expanded access to healthcare, advances in medical procedures, antibiotic medications, and the introduction of prenatal and neonatal care also improved the well-being of mothers and babies. Collectively, these developments translated into a startling $90 \%$ decline in the infant mortality rate and a 99\% decrease in the maternal mortality rate over the 20th century. Also, in the realm of maternal and child health, the 1900s ushered in the era of family planning. The availability of preconception counseling and contraceptive options paved the way for smaller families. Planned pregnancies and prenatal care combined to lower rates of fetal, infant, and maternal deaths.

The United States made strides to improve the safety of foods and the purity of the water supply. The introduction of safer and healthier foods had the dual effects of decreasing food contamination and improving the nutritional content of foods. The ability to identify vital micronutrients and to fortify foods led to the virtual elimination of nutritional deficiency diseases in childhood. As examples, in the United States, diseases such as rickets, pellagra, and goiter have vanished.

\section{WATER FLUORIDATION}

In the mid-20th century, the United States began to fluoridate the drinking water, reaching more than half the population by the end of the century. This public health action benefits people across the socioeconomic spectrum. As a result of this simple low-cost action, rates of tooth decay in children and tooth loss in adults were reduced by more than half.

\section{SAFER WORKPLACES}

During the 20th century, major reductions were achieved in rates of work-related injuries and deaths in the mining, construction, and manufacturing sectors. Toxic and disease-producing exposures to hazardous materials, poisons, dusts, fumes, and carcinogens in work settings have been monitored and significantly controlled. Worksite risk reduction occurred through combinations of regulations, installation of safety equipment, workforce training, use of personal protective equipment, attentive worker supervision, and when necessary, litigation.

\section{MOTOR VEHICLE SAFETY}

The introduction of the automobile and motorized transportation early in the 20th century redefined mobility, and simultaneously created new patterns of unintentional injury. In the United States, unintentional injury is the leading cause of death for people aged 1 to 44 years, and motor vehicle crash deaths have been one of two primary causes of injury deaths for decades. 


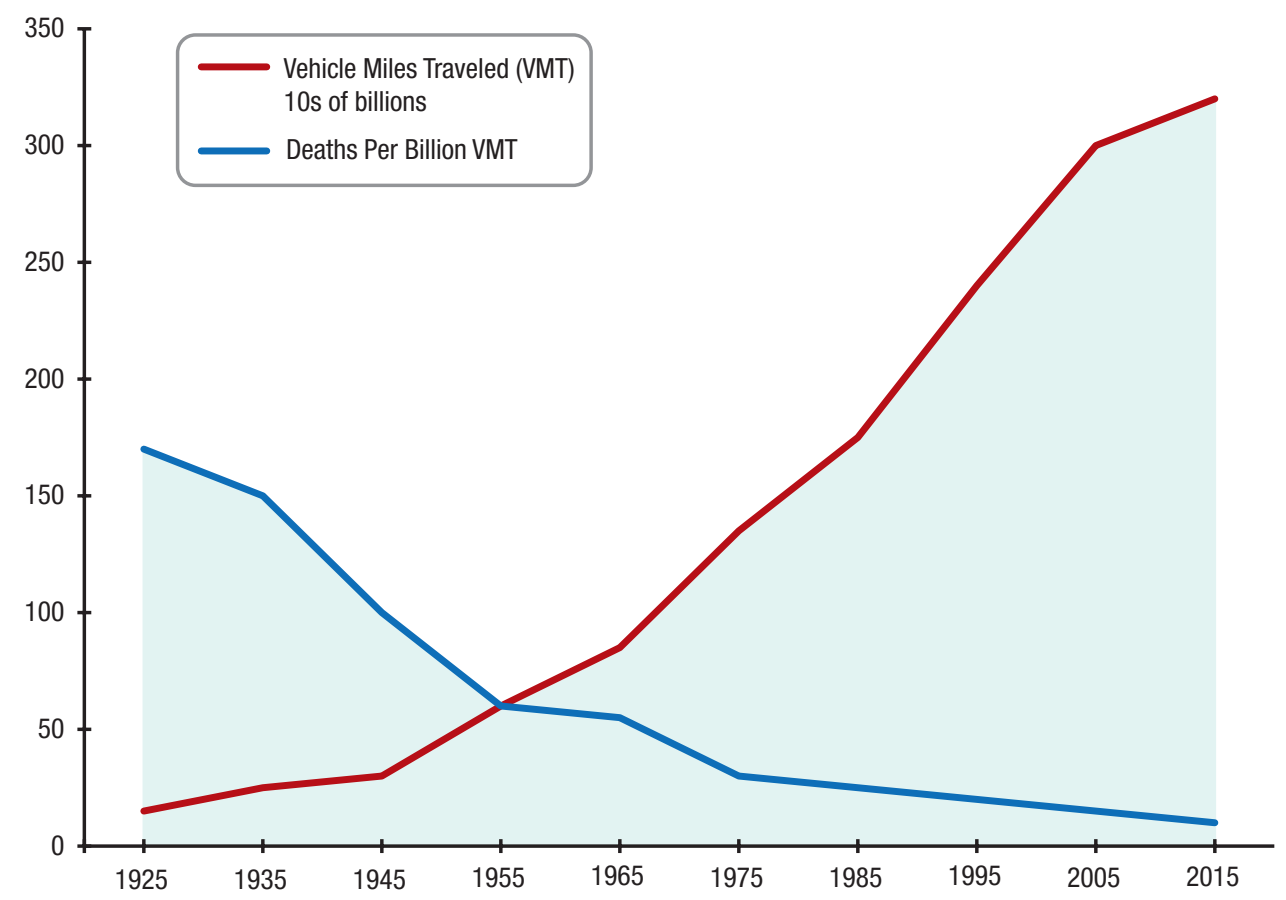

FIGURE 1.2 VMT and deaths per billion VMT, United States, 1925-2015.

VMT, vehicle miles traveled.

Source: Data from Bratland, D. (2018). US traffic deaths per VMT, VMT, per capita, and total annual deaths. Retrieved from https://commons.wikimedia.org/wiki/File:US_traffic_deaths_per_VMT,_VMT,_per_capita,_and_total_annual_ deaths.png

Fortunately, there are multiple pathways available for successfully mitigating motor vehicle crash trauma and death (Figure 1.2). This includes training motorists and passengers on every-time use of seat belts, child safety seats, and motorcycle helmets. Automobile manufacturers reengineered vehicles, replacing metals with plastic materials that became available in later decades. Safety technology rapidly evolved. Carmakers began to design vehicles with rigid passenger cages surrounded by deformable extremities. In a crash, the passenger compartment would remain intact while the bumpers and the motor or trunk compartments would collapse and absorb the impact.

The national highway system continuously upgrades the quality of roadways and highway lighting and introduces new signals, signage, and safeguards to make motoring safer. Onboard navigation systems and smart technologies are being used to alert drivers to dangerous situations and to diminish distractions. Laws have been passed to keep drivers in their lanes and driving within specified speed limits. Significant penalties are set for risky human behaviors including driving while under the influence of substances or while texting or using other electronics. New sensor technologies increasingly allow vehicles to sense-and avoid-road hazards including side-impact collisions, rapid deceleration of vehicles in front, and detection of persons or objects suddenly passing behind the vehicle. The evolving technology of the self-driving vehicle has been recently introduced and holds considerable future promise for decreasing collision risks.

\section{DECLINE IN DEATHS FROM CORONARY HEART DISEASE AND STROKE}

While rates of communicable diseases were declining, the numbers of cases of NCDs were increasing. Most notably, heart disease rates rose steadily during the first half of the 20th 
century. With the successful identification of modifiable lifestyle-related risk factors that were associated with heart disease, programs were devised for risk factor modification on an individual and population basis. A combination of decreased saturated fat intake in the habitual diet; improved detection, treatment, and control of high blood pressure; and smoking cessation contributed to steady, long-term declines in both stroke and ischemic heart disease mortality rates beginning in the 1960s and continuing for more than 50 years. By the 2010s, heart disease death rates were only slightly higher than cancer death rates for men and actually lower than cancer death rates for women. The downward trends in heart disease and stroke present a visible contrast to the relatively unchanging cancer death rates from the late 1970s onward (Figure 1.3).
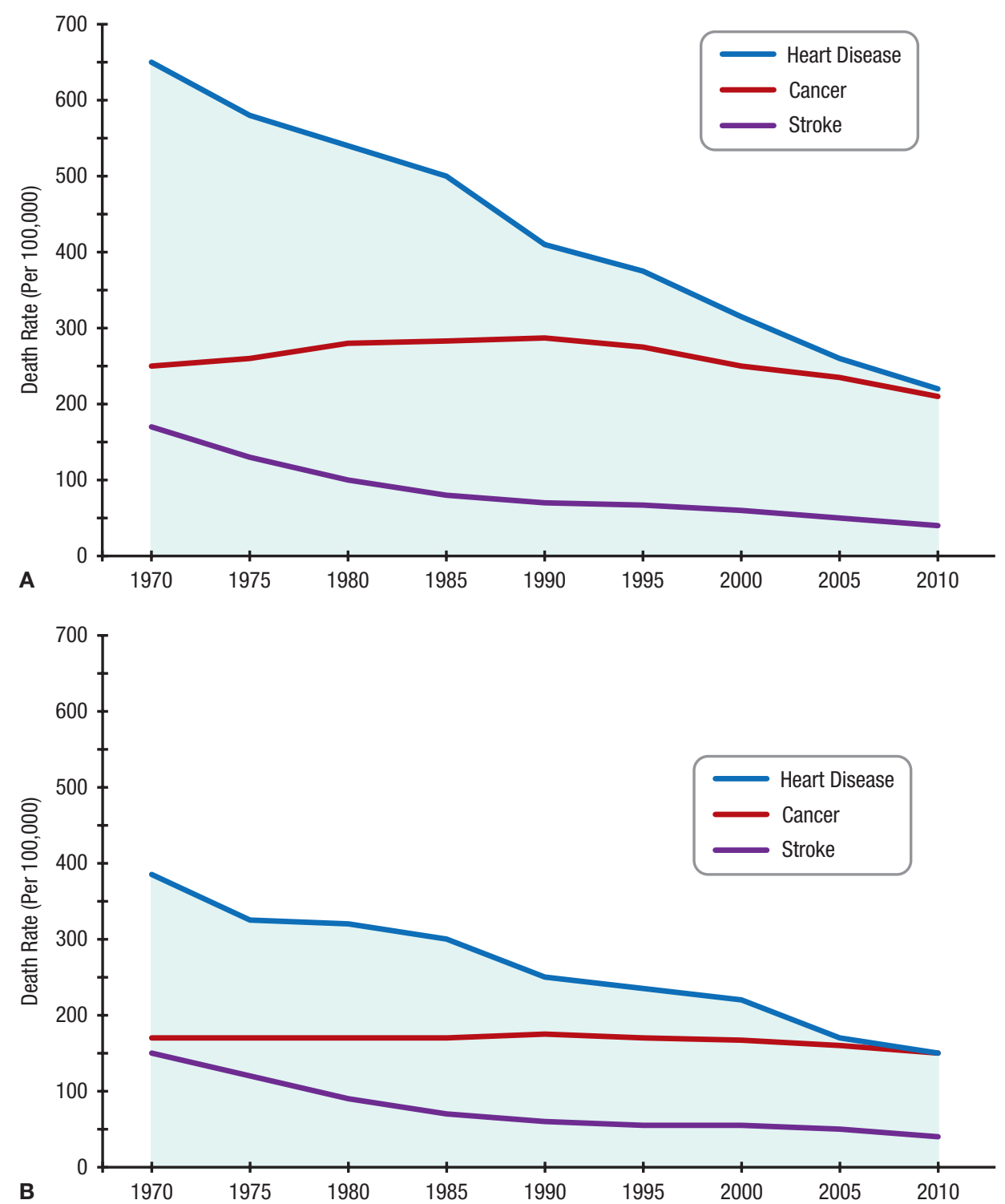

FIGURE 1.3 Trends in heart disease, cancer, and stroke deaths per 100,000 for (A) males and (B) females, United States, 1970-2010.

Source: Data from Ma J, Ward EM, Siegel RL, Jemal A. (2015). Temporal Trends in Mortality in the United States, 1969-2013. Original Investigation. JAMA. 2015;314(16):1731-1739. doi:10.1001/jama.2015.12319 


\section{RECOGNITION OF TOBACCO USE AS A HEALTH HAZARD}

The mass adoption of the cigarette smoking habit was a 20th century phenomenon. Shrewd marketing coupled with the addictive properties of nicotine led to a surge in smoking rates, first for men and later for women throughout the first half of the 1900s (Figure 1.4). Although by the late 20th century, cigarette smoking was described as the chief preventable cause of death in the United States, public recognition that tobacco posed a grave health hazard was slow to develop. One of the reasons is the 20-year time lag between rising smoking rates and rising deaths from smoking-related causes. This is due, in part, to the fact that it takes a matter of decades, on average, for a regular smoking habit to produce fatal cancer, respiratory disease, or cardiovascular disease.

Following the release of the landmark 1964 Surgeon General's Report on the health risks of smoking, there was an abrupt drop in numbers of smokers, followed by a longterm continuing downward trend in tobacco use. ${ }^{14}$

\section{PUBLIC HEALTH ACHIEVEMENTS CONTINUING INTO THE 2IST CENTURY}

Taken together, these public health achievements continue to produce favorable trends that have extended into the current 21 st century. In fact, the CDC presented an updated list of major public health achievements for the first decade of the 2000s. ${ }^{15}$

Seven are direct offshoots of the original list for the 20th century:

- Cardiovascular disease prevention

- Maternal and infant health

- Motor vehicle safety

- Occupational safety

- Prevention and control of infectious diseases

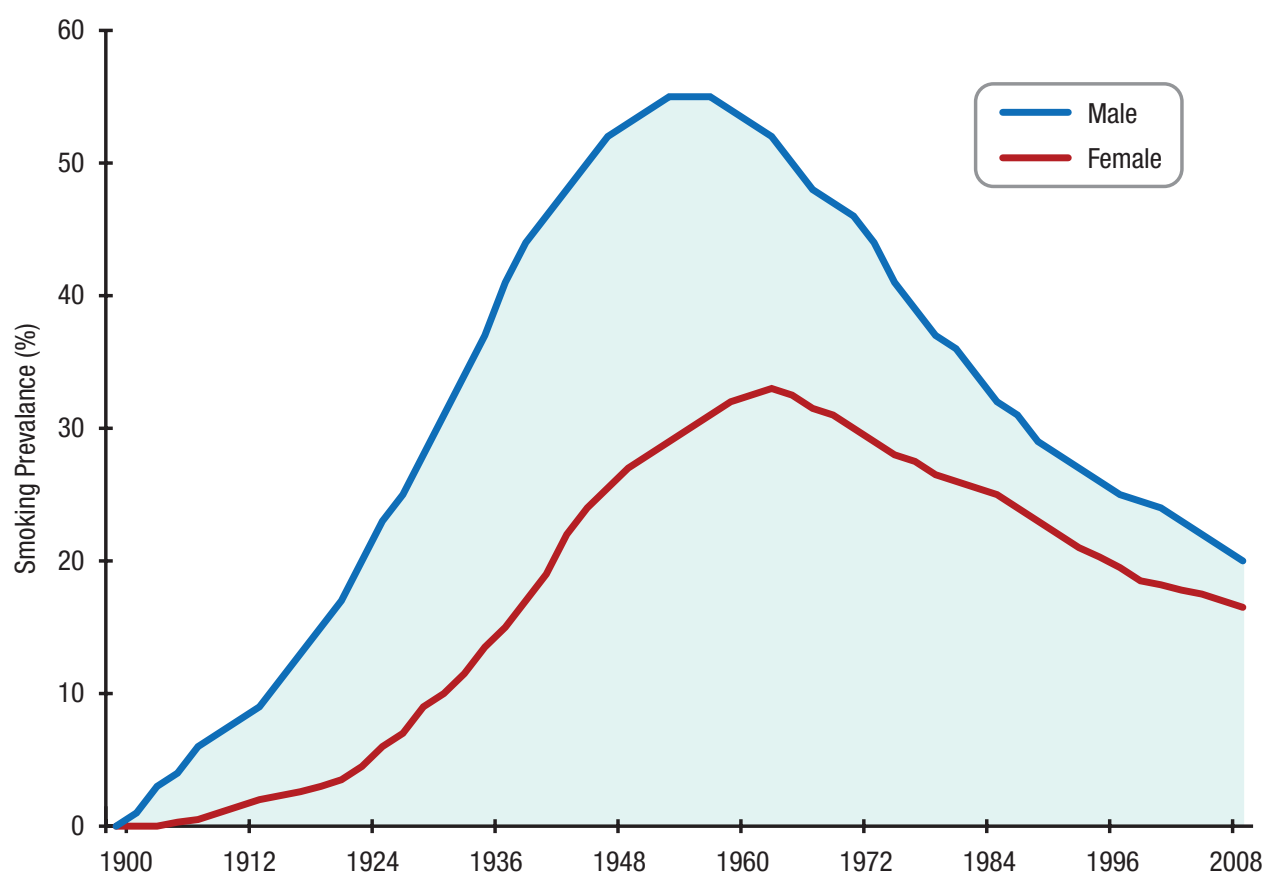

FIGURE 1.4 Cigarette smoking prevalence for males and females, United States, $1900-2010$. 
- Tobacco control

- Vaccine-preventable diseases

Three new achievements have been swapped into the roster:

- Cancer prevention

- Childhood lead poisoning prevention

- Improved public health preparedness and response

The new additions include public health preparedness that became a priority following the September 11, 2001 terrorist attacks. The other two new achievements are in the areas of prevention of cancer and childhood lead poisoning.

\section{UNDERSTANDING HEALTH AND DISEASE}

\section{CLASSIFYING DISEASE}

Disease signals that something is amiss and not fully healthy, creating an opportunity for a person's disorder to be detected, diagnosed, named, and classified.

International systems have been developed for systematic disease categorization. In 2018, the WHO released a draft of its landmark 11 th Revision of the International Statistical Classification of Diseases and Related Health Problems (ICD-11) ${ }^{16}$ The WHO aims for ICD-11 to map the human condition from birth to death: any injury or disease we encounter in life-and anything we might die of — is coded. ${ }^{17}$ Diseases are listed numerically with numbers pertaining to larger disease categories such as neoplasms (cancers), diseases of the circulatory system, diseases of the respiratory system, and mental/behavioral/neurodevelopmental disorders.

Important terminology that is quite common in public health is the notion of communicable as compared with noncommunicable disease (NCD). Communicable disease refers to disease that is passed from an infected person, a person who harbors an infectious agent (such as a bacteria or virus), to a previously-noninfected person. The movement of the infectious agent is necessary for causing disease. In contrast, an NCD, sometimes called a nontransmissible disease, is partly defined by what it is not. An NCD is characterized by an absence of contagion or communicability. With NCDs, there is a lack of evidence for person-to-person transmission via contagion, or a vector, or biological inheritance. The term NCD is now preferred to the less specific term, chronic disease. As we observe, NCDs now dominate the disease landscape in higher-income countries and the term "noncommunicable" is not precisely accurate because these diseases are transmitted between people through social interactions as well. Among NCDs, diseases of the heart and cancers are especially prominent worldwide.

\section{THE GLOBAL BURDEN OF DISEASE}

Understanding the global landscape of health and disease is a worldwide scientific enterprise. The Global Burden of Diseases, Injuries, and Risk Factors Study (GBD) engages 3,600 researchers from more than 145 countries to examine trends in health indicators. ${ }^{18}$

Rates of mortality are decreasing worldwide. This is good news that is closely tied to longer life expectancy. However, rates of disability and various forms of impairment are steadily rising in part because people are living longer. The GBD is premised on the idea that all world citizens deserve to live a long life in full health. The primary metric used in the GBD, the disability-adjusted life year (DALY), is used to compare 
hundreds of diseases and injuries in terms of risks for dying early and/or living with decreased capacity and quality of life due to disability. For each health condition, the GBD quantifies both years of life lost (YLLs) and years lived with disability (YLDs) and adds them together to estimate DALYs. Premature death is measured as YLLs. Living with diminished health and functionality is quantified as YLDs. Putting these together for each health condition, DALYs = YLLs + YLDs. One DALY equals one lost year of healthy life.

DALYs: disability-adjusted life years

One DALY equals one lost year of healthy life.

For each disease or medical condition, DALYs are made up of two components:

1. Dying early-premature death-is measured as years of life lost (YLLs).

2. Living with decreased capacity and quality of life due to disability is measured as years lived with disability (YLDs).

These two pieces are added together to get DALYs:

DALYs $=$ YLLS + YLDs

A DALY is described as a universal metric that compares and contrasts health conditions affecting a diversity of populations across time. The GBD investigators use DALYs to estimate the years of healthy life lost by type of health condition and by risk factor on multiple levels: country, region, and worldwide. One aim of the GBD is to equip decision makers with the necessary evidence to confront health issues that detract from healthy life. A related aim is to carefully allocate resources, professional talent, and funding to this cause.

So, what are the commonest forms of illness/disability contributing to the global burden of disease? When comparing the leading causes of DALYs globally for 1990 and 2017, the variety of diseases is notable (Table 1.1). Neonatal disorders represent the top-ranking cause of DALYs in both years. Lower respiratory infections (pneumonia and influenza) are the highest-ranking among infectious diseases. Compared to 1990, in 2017, there were more NCDs (5 rather than 3), especially featuring ischemic heart disease and stroke as the second and third leading causes of DALYs. The trade-off is that numbers of communicable diseases in the top 10 decreased from 4 in 1990 to 2 in 2017 . Only one injury cause of DALYs - road injuries-is ranked on the top 10 lists for both years.

Figure 1.5 displays DALYs in three major categories-NCDs, communicable diseases/ neonatal disorders, and injuries. ${ }^{19}$ Globally (vertical bar on the left), nearly two-thirds of DALYs come from NCDs, with the most prominent being ischemic heart disease, stroke, diabetes, and chronic obstructive pulmonary disease. Also contributing to DALYs in the NCD category are mental health conditions, musculoskeletal disorders, pain-related syndromes, and sense-organ ailments. In the communicable/neonatal category, we have already seen that neonatal disorders top the list, added to lower respiratory diseases, diarrheal diseases, tuberculosis, and diseases of malnutrition. Road injuries and falls are the primary causes of DALYs within the injury category.

The other 2 bars in Figure 1.5 display a clear distinction between causes of DALYs in low-sociodemographic index (SDI) countries compared with high-SDI nations. ${ }^{20}$ LowSDI countries include Haiti in the Western hemisphere and many sub-Saharan nations 


\section{TABLE 1.1 Top 10 Leading Causes of DALYs Worldwide, 1990 and 2017}

\begin{tabular}{|c|l|l|}
\hline & 1990 & 2017 \\
\hline 1 & Neonatal disorders & Neonatal disorders \\
\hline 2 & Lower respiratory infections & Ischemic heart disease \\
\hline 3 & Diarrheal diseases & Stroke \\
\hline 4 & Ischemic heart disease & Lower respiratory infections \\
\hline 5 & Stroke & Chronic obstructive pulmonary disease \\
\hline 6 & Congenital birth defects & Diarrheal diseases \\
\hline 7 & Road injuries & Diabetes mellitus \\
\hline 8 & Tuberculosis & Road injuries \\
\hline 9 & Chronic obstructive pulmonary disease & Low back pain \\
\hline 10 & Measles & Congenital birth defects \\
\hline
\end{tabular}

DALYs, disability-adjusted life years.

\begin{tabular}{|l|}
\hline Legend: \\
\hline Noncommunicable diseases (NCDs) \\
\hline Maternal and neonatal conditions \\
\hline Communicable and nutritional conditions \\
\hline Injuries \\
\hline
\end{tabular}

in Africa. For low-SDI countries, communicable diseases and neonatal and nutritional disorders account for the largest share of DALYs. In sharp contrast, for such high-SDI nations as the United States and Western Europe, NCDs produce almost 85\% of DALYs and communicable diseases contribute less than $10 \%$.

When comparing the leading causes of YLDs globally for 1990 and 2017, we see a strong preponderance of NCD conditions in both years (Table 1.2). Remember that the YLD measure focuses on disability rather than death, so here, the prominent causes feature low back and headache pain, sense organ disorders (hearing, vision), and mental disorders (depression, anxiety).

Major contributors of DALYs also shift over time. For example, NCDs contribute to DALYs directly because premature deaths from NCDs get tallied as YLLs. NCDs also contribute to DALYs through increasing YLDs. NCDs are lifestyle-related diseases with risk factors that cluster and worsen, leading to more days of disability. Also, prior to death, many NCDs produce significant nonfatal episodes of illness and injury (heart attacks, strokes, or falls leading to fractures) that are severely disabling. So, chronologically across the life course of many individuals, before NCDs contribute to YLLs from premature death, they contribute in a major way to YLDs from years of suboptimal living with a disability. 


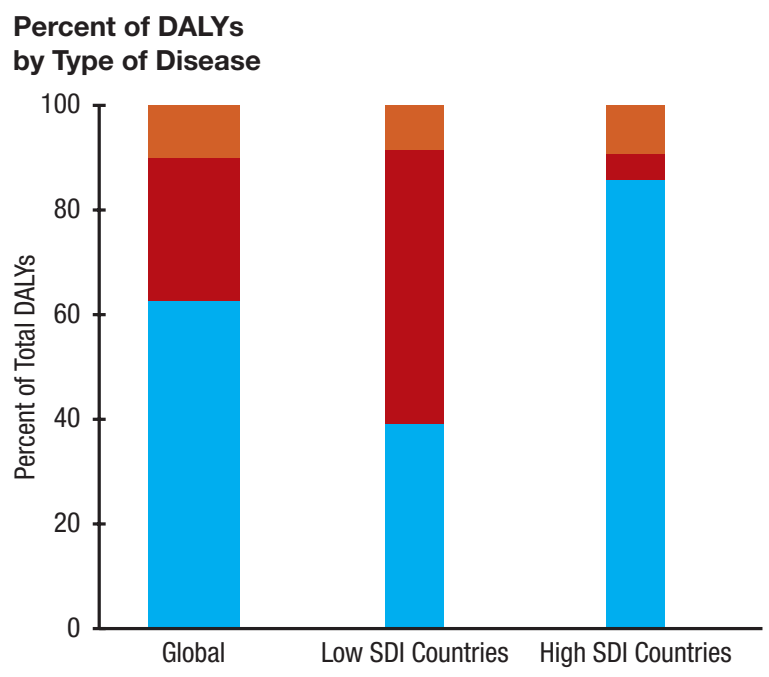

DALYs, disability-adjusted life years; SDI, sociodemographic index.

Source: Data from GBD Compare-IHME Viz Hub. Institute for Health Metrics and Evaluation (IHME). Retrieved from https://vizhub.healthdata.org/gbd-compare/.

\section{TABLE 1.2 Top 10 Leading Causes of YLDs Worldwide, 1990 and 2017}

\begin{tabular}{|c|l|l|}
\hline & 1990 & 2017 \\
\hline 1 & Low back pain & Low back pain \\
\hline 2 & Headache disorders & Headache disorders \\
\hline 3 & Dietary iron deficiency & Depressive disorders \\
\hline 4 & Depression & Diabetes mellitus \\
\hline 5 & Chronic obstructive pulmonary disease & Age-related and other hearing loss \\
\hline 6 & Age-related and other hearing loss & Chronic obstructive pulmonary disease \\
\hline 7 & Anxiety disorders & Dietary iron deficiency \\
\hline 8 & Blindness and vision impairment & Blindness and vision impairment \\
\hline 9 & Diabetes mellitus & Neonatal disorders \\
\hline 10 & Other musculoskeletal disorders & Other musculoskeletal disorders \\
\hline
\end{tabular}

YLDs, years lived with disability.

Source: From Global, regional, and national incidence, prevalence, and years lived with disability for 310 diseases and injuries, 1990-2015: a systematic analysis for the Global Burden of Disease Study 2015 https://www.thelancet.com/pdfs/journals/lancet/ PIIS0140-6736(16)31678-6.pdf

\begin{tabular}{|l|}
\hline Legend: \\
\hline Noncommunicable diseases (NCDs) \\
\hline Maternal and neonatal conditions \\
\hline Communicable and nutritional conditions \\
\hline
\end{tabular}




\section{LEADING CAUSES OF DEATH IN THE UNITED STATES}

Between 1900 and the early decades of the 2000s, the number of U.S. deaths per 1,000 citizens per year dropped by half, from 17.2 deaths per 1,000 in 1900 to 8.5 deaths in 2016. The top 10 causes of death in the United States transformed in a remarkable fashion (Figure 1.6). ${ }^{21,22}$ In the year 1900, four infectious diseases-pneumonia/influenza,
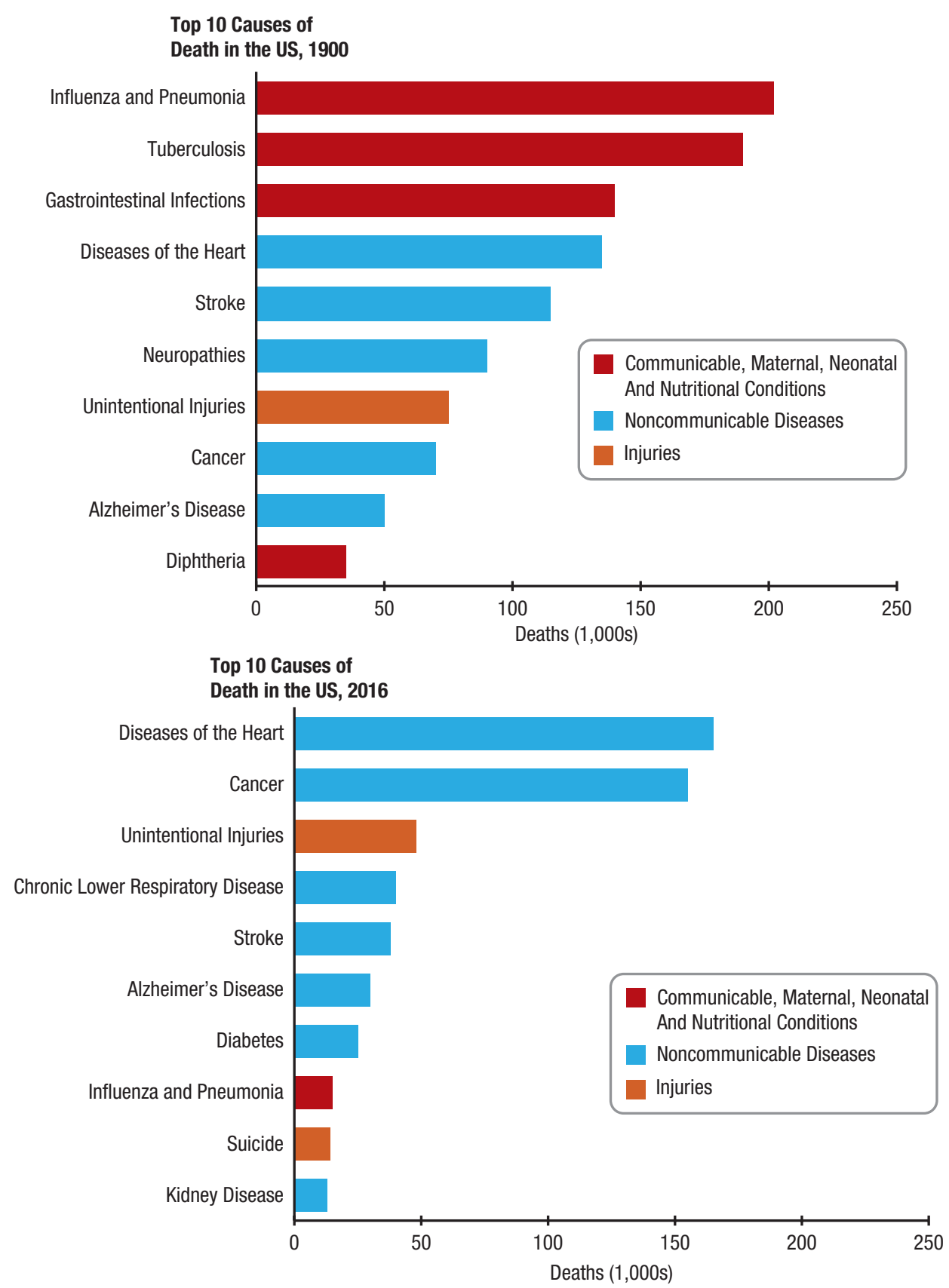

FIGURE 1.6 Top 10 causes of death, United States, 1900 and 2016.

Source: Data from Jones DS, Podolsky SH, Greene JA. The Burden of Disease and the Changing Task of Medicine. N Engl J Med. 2012;366(25):2333-2338. doi:10.1056/NEJMp1113569; Heron M. National Vital Statistics Reports, Deaths: Leading Causes for 2016; 2016. Retrieved from https://www.cdc.gov/nchs/data/nvsr/nvsr67/nvsr67_06.pdf. 
tuberculosis, gastrointestinal infections, and diphtheria-were all ranked among the top 10. These infectious diseases collectively accounted for more deaths per 1,000 U.S. citizens in 1900 than the full top 10 list in 2016 together. In contrast, only a single infectious disease cause of death appears among the top 10 in 2016 (pneumonia and influenza). In 2016, the major burden of disease mortality came from lifestyle-related NCDs, most notably heart disease and cancers.

In 2016, the top 10 causes of death in the United States ranked heart disease first with cancer a close second (Figure 1.3), with each accounting for almost one-quarter of U.S. deaths. No other cause of death came close. Unintentional injuries, chronic lower respiratory disease, and stroke filled out the top five. Alzheimer's disease and diabetes ranked sixth and seventh. The final three among the top 10 were influenza and pneumonia, suicide, and kidney disease. Overall, lifestyle-related NCDs accounted for seven of the top 10 causes of death in 2016.

\section{LEADING CAUSES OF DEATH GLOBALLY}

According to the GBD database for 2017, two cardiovascular diseases topped the list of leading causes of death globally (Table 1.3). ${ }^{23}$ Ischemic heart disease ranked first, followed by stroke. COPD ranked third (this is the same diagnosis as chronic lower respiratory disease in the U.S. classification). Fourth in order, lower respiratory infections primarily include pneumonia and influenza. Alzheimer's disease was fifth in rank. The sixth through

\section{TABLE 1.3 Top 10 Leading Causes of Death Worldwide, 1990 and 2017}

\begin{tabular}{|c|l|l|}
\hline & 1990 & 2017 \\
\hline 1 & Ischemic heart disease & Ischemic heart disease \\
\hline 2 & Stroke & Stroke \\
\hline 3 & Lower respiratory infections & Chronic obstructive pulmonary disease \\
\hline 4 & Neonatal disorders & Lower respiratory infections \\
\hline 5 & Chronic obstructive pulmonary disease & Alzheimer's disease and other dementias \\
\hline 6 & Diarrheal diseases & Tracheal, bronchus, and lung cancer \\
\hline 7 & Tuberculosis & Neonatal disorders \\
\hline 8 & Road injuries & Diarrheal diseases \\
\hline 9 & Tracheal, bronchus, and lung cancer & Diabetes mellitus \\
\hline 10 & Alzheimer's disease and other dementias & Cirrhosis and other chronic liver diseases \\
\hline
\end{tabular}

\begin{tabular}{|l|}
\hline Legend: \\
\hline Noncommunicable diseases (NCDs) \\
\hline Maternal and neonatal conditions \\
\hline Communicable and nutritional conditions \\
\hline Injuries \\
\hline
\end{tabular}




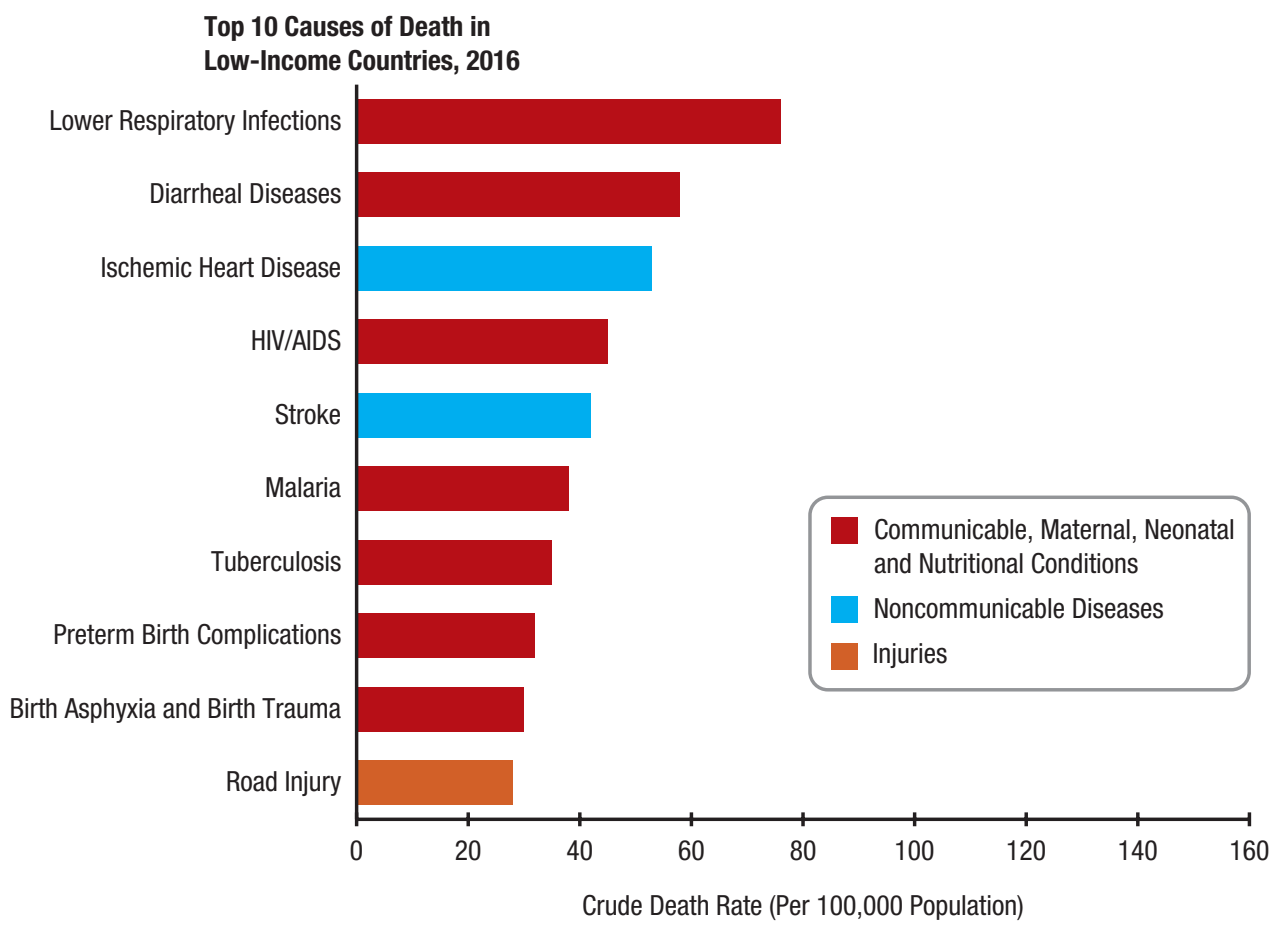

Top 10 Causes of Death in Upper-

Middle-Income Countries, 2016

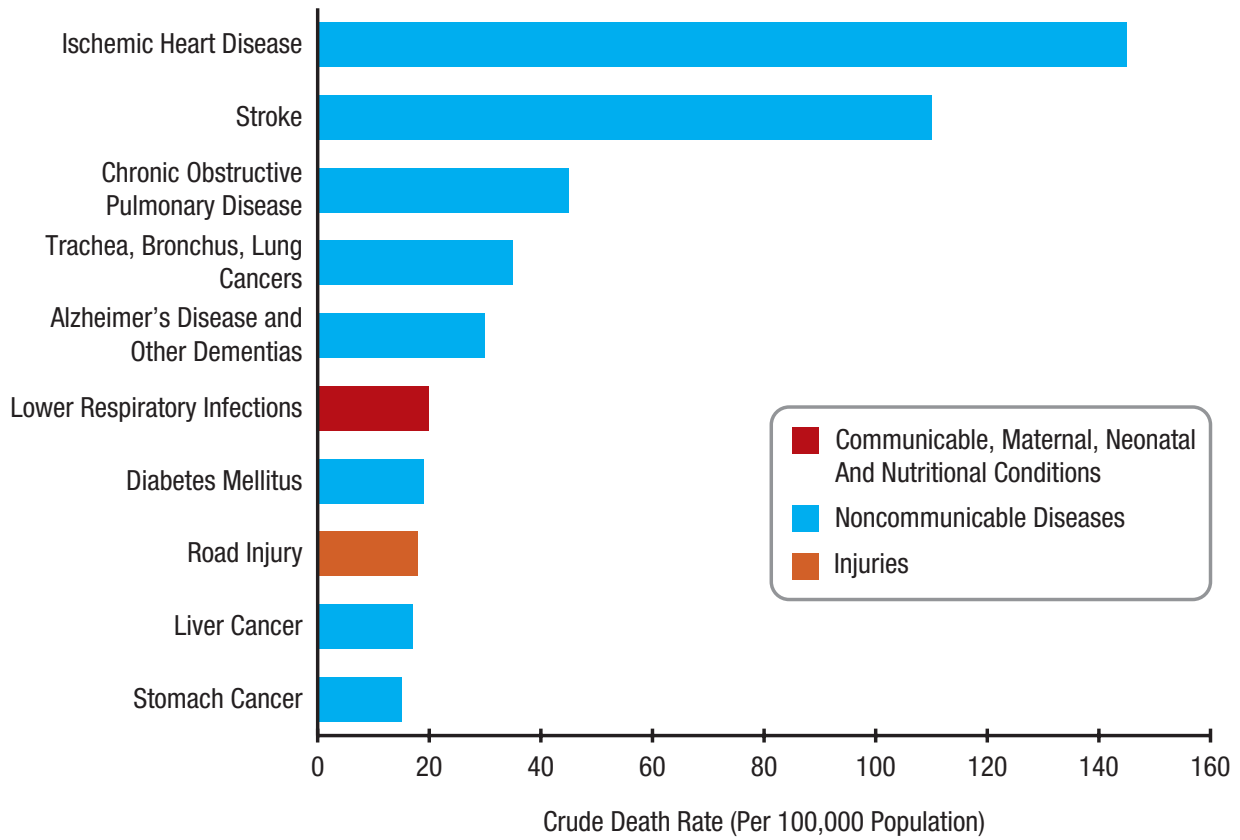

FIGURE 1.7 Top 10 global causes of death by World Bank income category (low income, lower-middle income, upper-middle income, and high income), 2016. (continued)

Source: Reproduced with permission from the World Health Organization. The top 10 causes of death. (2018). https://www.who.int/news-room/fact-sheets/detail/the-top-10-causes-of-death 

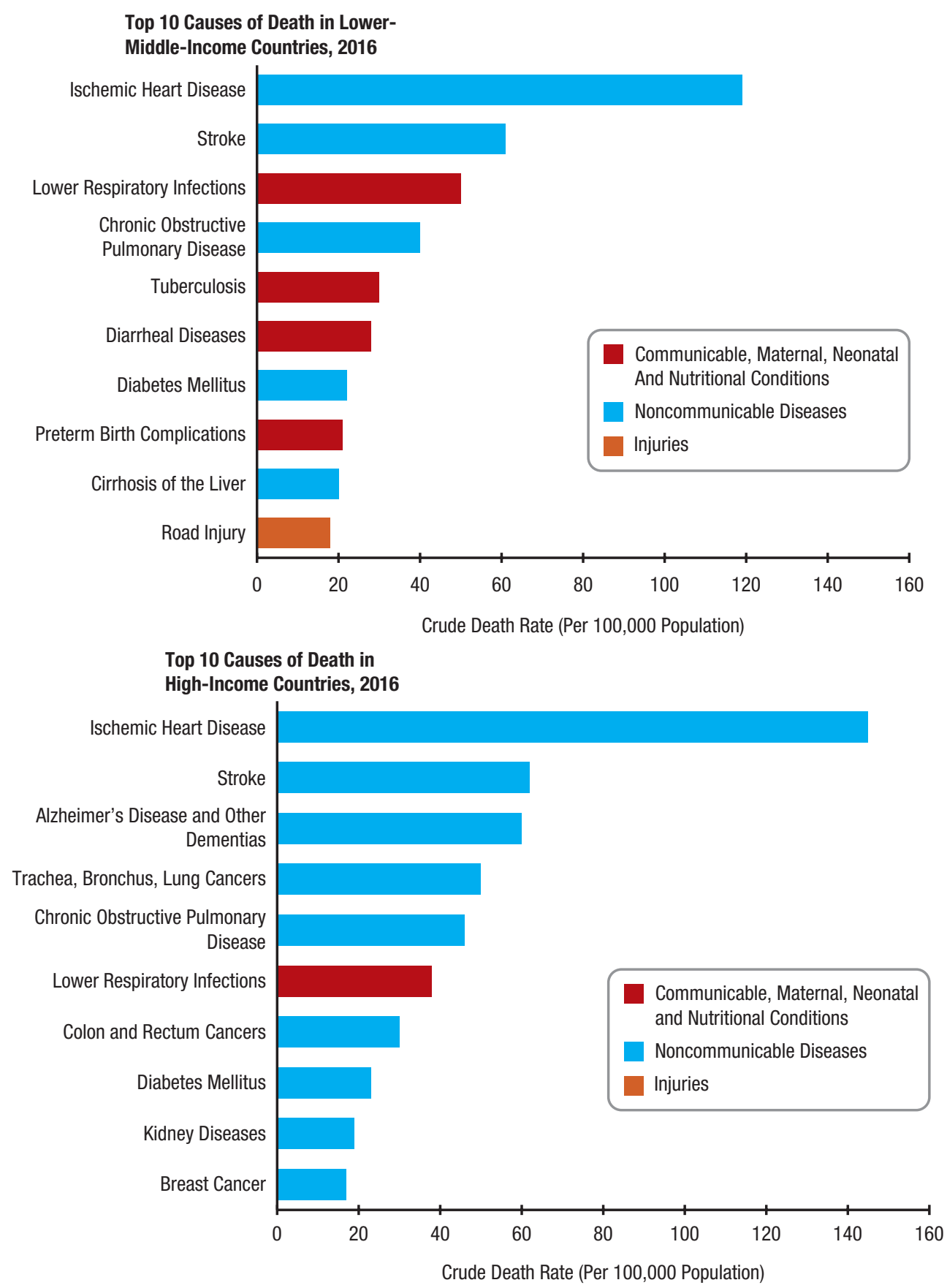

\section{FIGURE 1.7 (continued)}

tenth leading causes were cancer of the lung, neonatal disorders, diarrheal diseases, diabetes, and cirrhosis and related liver disorders.

When comparing the leading causes of death globally for 1990 and 2017, it is notable that NCDs are more numerous and higher ranking in 2017.

Examining global mortality patterns in greater detail, when countries are classified and divided into four World Bank income categories (low, lower-middle, upper-middle, and high income), trends and distinctions become readily apparent (Figure 1.7). ${ }^{24}$ 
Here is a series of observations that you can confirm for yourself.

First, communicable disease causes of death are particularly concentrated in low-income countries where 7 of 10 causes of death are infectious diseases. At the other extreme, for high-income countries, only a single infectious disease, lower respiratory infectionsprimarily influenza and pneumonia-appears among the top 10.

Second, not unexpectedly, in the high-income countries, NCD causes of death predominate and account for 9 of 10 leading causes of death. At the opposite pole, for low-income countries, only 2 of 10 top causes are NCDs: ischemic heart disease and stroke.

Third, as one observed commonality, cardiovascular diseases are the leading causes of death in lower-middle, upper-middle, and high-income countries. In each category, ischemic heart disease ranks first and stroke ranks second. Now contrast this with low-income countries where ischemic heart disease ranks third and stroke is in fifth place.

Fourth, it is useful to ask, how different are these specific causes of death across income categories? The answer is very different. In fact, only three causes of death share the top 10 in both low-income and high-income countries. These three are ischemic heart disease, stroke, and lower respiratory infections.

\section{THE U.S. PUBLIC HEALTH SYSTEM}

The public health system in the United States is organized across federal, state, municipal, and local health authorities. Other public health services are delivered by nongovernmental agencies and community programs.

\section{THE U.S. FEDERAL PUBLIC HEALTH SYSTEM}

The U.S. federal public system resides under the executive branch of government, principally concentrated within the Department of Health and Human Services (HHS), although health-related functions are also performed by the Departments of Defense, Veterans Affairs, Homeland Security, and Labor, and the Social Security Administration.

The stated mission of the HHS is to enhance and protect the health and well-being of all Americans. ${ }^{25}$ HHS seeks to achieve this mission in several ways. Not only does HHS deliver a range of health and human services, the Department also actively promotes advances in public health and medical research and carries out aspects of health policy. The Office of the Secretary includes a complement of administrative officers. ${ }^{26}$ Among these are the Assistant Secretary of Health who oversees the office of the U.S. Surgeon General. ${ }^{27}$ In the post-September 11 era, when public health preparedness became a priority public health issue, a new office was created to house the Assistant Secretary for Preparedness and Response (ASPR). ${ }^{28}$

Better known to the general public are several of the HHS operating divisions. Those with a high degree of name recognition include the $\mathrm{CDC},{ }^{29}$ the $\mathrm{NIH},{ }^{30}$ and the FDA. ${ }^{31}$ The Centers for Medicare and Medicaid Services (CMS) is rarely mentioned by name but its component programs, Medicare and Medicaid, are broadly known. ${ }^{32} \mathrm{CMS}$ performs one of the most essential functions of HHS, administering the major federal healthcare funding programs for older adults (Medicare) and for low-income families, pregnant women, people of all ages with disabilities, and people who need long-term care (Medicaid). Another division, the Substance Abuse and Mental Health Services Administration (SAMHSA), supports advances in substance abuse treatment and prevention programs. ${ }^{33}$ The HHS is also charged with providing healthcare to First Nations Americans residing on government lands through the Indian Health Services. ${ }^{34}$ 


\section{STATE, MUNICIPAL, AND LOCAL HEALTH AUTHORITIES}

Much of the direct delivery of public health services to individual recipients occurs at state, county, and especially, city, and municipality levels. Correspondingly, the majority of government public health professionals work in state, county, and local health departments close to their places of residence.

Apart from the practicality of bringing services directly to the people, this structure aligns with the tradition, since the founding of the nation, of vesting significant governing power in the states. In the case of public health, where needs reach down to the community, the family unit, and the individual, the provision of public health programs and services is shared among state and local levels. The specific division of labor and the delegation of duties between state and local levels differ across states.

\section{GLOBAL PUBLIC HEALTH}

On an international level, the WHO is the body charged with governance of health on a global scale. Moreover, public health services are also delivered by national and international nongovernmental agencies and community programs around the globe.

\section{THE WORLD HEALTH ORGANIZATION}

The WHO is part of the United Nations (UN) system. ${ }^{35}$ The WHO is the organization most directly involved in global health. However, many other agencies also participate in functions that bear directly on the health of populations. This includes women's health (UN Women), ${ }^{36} \mathrm{HIV} / \mathrm{AIDS}$ (UNAIDS), ${ }^{37}$ drug abuse (UNODC), ${ }^{38}$ refugee health (UNHCR and UNRWA), ${ }^{39,40}$ children's health (UNICEF), ${ }^{41}$ and famine prevention/intervention through the World Food Programme (WFP), ${ }^{42}$ among other entities.

Established in 1948 and headquartered in Geneva, Switzerland, the WHO has six regional offices and 150 country offices. For example, the Pan American Health Organization (PAHO), ${ }^{43}$ based in Washington, DC, is actually the WHO regional office for the entire Western Hemisphere, the "Americas."

The WHO addresses health needs that may be brought forward by any of the 194 UN member states. The organization has 7,000 staff members worldwide, and more than 700 institutions support the WHO's work.

\section{GLOBAL NGOS AND CIVIL SOCIETY}

Many thousands of national and international NGOs focus their activities on some aspect of public health. We have discussed the major causes of death and disability globally, each of which carries effects for the families, social networks, and communities most affected. This has prompted the proliferation of organizations at local, national, and international levels that bring focus and funding to a specific health issue.

Name a major disease, and there will be an organization advocating for the cure. Consider cancer. There are so many nongovernmental and community-based organizations that an online index was created to catalogue hundreds of these. Well known is the American Cancer Society. ${ }^{44}$ There are counterpart cancer organizations beginning with the name of dozens of other nations (e.g., Dutch Cancer Society, Saudi Cancer Society) ${ }^{45,46}$ Many organizations have a focus on a specific cancer. In the United States, Susan G. Komen for the Cure is well known for fund-raising for breast cancer using community walks and running events to garner community participation. ${ }^{47}$ Major cancer killer diseases (lung, breast, colorectal) have organizations; so too do little-known 
cancers (Acoustic Neuroma Association is first listed on the alphabetical index of 345 organizations).$^{48}$

In parallel, other prominent diseases have engendered associations that seek funding for research and offer support to persons living with the disease and their family members. Considering the leading causes of death in the United States, there is the American Heart Association, ${ }^{49}$ American Cancer Society, ${ }^{44}$ American Lung Association, ${ }^{50}$ American Diabetes Association, ${ }^{51}$ and the Alzheimer's Association. ${ }^{52}$ There are associations for surviving family members who have lost a loved one to drunk driving (Mothers Against Drunk Driving), ${ }^{53}$ gun violence (The Sandy Hook Promise), ${ }^{54}$ and suicide (Alliance of Hope).$^{55}$

There are health professional organizations for public health (APHA) ${ }^{56}$ and for most every type of health and medical professional. Some NGOs represent an occupation (American Medical Association) ${ }^{57}$ while others represent a specific specialty (American Psychiatric Association $)^{58}$ or even subspecialty (Academy of Consultation-Liaison Psychiatry). ${ }^{59}$

By way of example, disasters, humanitarian emergencies, and public health crises bring together governmental and nongovernmental entities to assist populations in need. ReliefWeb serves as an international online hub and information resource, helping to coordinate humanitarian assistance for specific disaster events. ${ }^{60}$ ReliefWeb lists more than 3,000 organizations that may be active in disasters. Well known among NGOs and international nongovernmental organizations (INGOs) are the American Red Cross, ${ }^{61}$ International Federation of Red Cross and Red Crescent Societies, ${ }^{62}$ CARE, ${ }^{63}$ Caritas, ${ }^{64}$ and Doctors Without Borders (Médecins Sans Frontières). ${ }^{65}$ Large numbers of religiouslyaffiliated NGOs also operate in this space (e.g., Catholic Charities USA, Episcopal Relief and Development, Lutheran World Relief, and Mennonite Central Committee). ${ }^{66-69}$

The interconnection and coordination among governmental and nongovernmental entities will be a recurring theme as we explore the science and practice of population health.

Now we embark on an introduction to public health thinking, considering the common behavior of drinking alcohol from individual and population health points of view (Case Study 1.1). In addition, although not expanded upon in the text, you can access a podcast (labeled Case Study 1.2), providing a second example of population health thinking dealing with HIV/AIDS by following this link to Springer Publishing Company Connect ${ }^{\mathrm{TM}}$ : https://connect.springerpub.com/content/book/978-0-8261-7754-4/front-matter/ fmatter5).

\section{CASE STUDY 1.1: POPULATION HEALTH THINKING}

One of the most important skills to acquire in population health thinking is to be able to think in terms of populations, to understand that the causes of health in populations are different than the causes of health in individuals. ${ }^{2}$ The following is an illustration of why it is important to develop this facility.

Alcohol use is common and normative in the United States. In fact, according to the 2015 National Survey on Drug Use and Health (NSDUH), 86.4\% of people aged 18 or older reported that they drank alcohol at some point in their lifetime. In terms of recency, $70.1 \%$ reported drinking alcohol in the past year and $56.0 \%$ reported drinking in the past month. ${ }^{70}$

Underage drinking is also common, with $22.7 \%$ of survey respondents, aged 12 to 17 , indicating that they drank alcohol in the past year. Underage drinking is of considerable public health concern. ${ }^{71}$ The CDC has estimated that alcohol is a risk factor for the deaths of more than 4,000 youth annually from alcohol-involved motor vehicle crashes, homicides, suicides, and unintentional poisonings. Drinking is associated with almost 200,000 nonfatal injuries in persons under age 21. Moreover, 
drinking impairs judgment in a manner that may increase risk for unprotected sexual behavior, experimentation with other drugs, physical and sexual assault, aggressive and criminal behavior, and drinking and driving. Early-onset drinking may also interfere with brain development during the critical period of adolescence and young adulthood. Also, those who begin to drink alcohol before the age of 15 are four times more likely to progress to alcohol dependence later in their life span. In turn, alcohol dependence is associated with elevated risks for a range of chronic diseases and premature death.

So, what are the causes of early initiation and maintenance of regular drinking behavior at the individual level? Early experimentation with alcohol use, as well as use of other substances, tends to be determined by influences close to the individual. These include the drinking behaviors of family members in the household and friends who are socially-important members of the individual's peer group and social network. Initial alcohol use occurs during the adolescent years, coinciding with the period of social development when peer influences are salient and powerful.

There may be counterbalancing influences that decrease the likelihood of adolescents and young adults engaging in drinking behavior. For example, youth who participate in team and community sports are frequently prohibited from drinking, smoking, or other substance use, under penalty of disqualification to compete or expulsion from the team.

The environmental context also exerts its influences on individual choices around drinking alcohol. For example, in some peer networks, youth may invite friends to parties in their homes when their parents are away or find other unsupervised venues for social events that feature alcohol. Underage youth have almost no problems obtaining alcohol. In fact, $95.1 \%$ of youth, aged 12 to 14 years, who reported drinking indicated that they had received their most recent drinks for free. ${ }^{70}$ Alcohol is readily available from family members and friends, including older peers who can legally buy alcohol, and often alcohol is stored in the home, within easy reach.

Also, there are additional influences in the immediate environment. For example, studies have shown clearly that the density of alcohol outlets in the neighborhood is a strong determinant of levels of hazardous drinking as well as drinking by youth and young adults in the local community. ${ }^{72,73}$ In fact, this reality has led to the development of interventions to reduce the density of alcohol outlets as a means of concomitantly reducing excessive alcohol consumption and attendant health risks. ${ }^{74,75}$

Therefore, causes at all levels of the eco-social model, which we discuss in Chapter 2, What Causes Health of Populations? An Eco-Social and Life Course Approach, ranging from peer influences to alcohol outlets close to one's home, can contribute to the risk of drinking. But now we ask a different question: What are the causes of prevalence of drinking in the population overall? The answer here is quite different: What determines population-level drinking is really the availability of alcohol more broadly in society.

Globally, the highest rates of alcohol consumption and the highest rates of alcohol-attributable all-cause mortality are found in Russia and several eastern European countries (Figure 1.8). These nations experience widespread alcohol-related disease, early death, and detrimental social patterns related to the effects of consuming alcohol.

On the ladder of alcohol consumption, per capita consumption is also moderately high throughout western Europe, while the United States and much of the Americas exhibit an intermediate level of consumption. Laws operate on a macro level to limit alcohol consumption both in terms of specifying the legal age for drinking and meting out consequences for alcohol-related violations. This includes severe penalties for driving while intoxicated. 


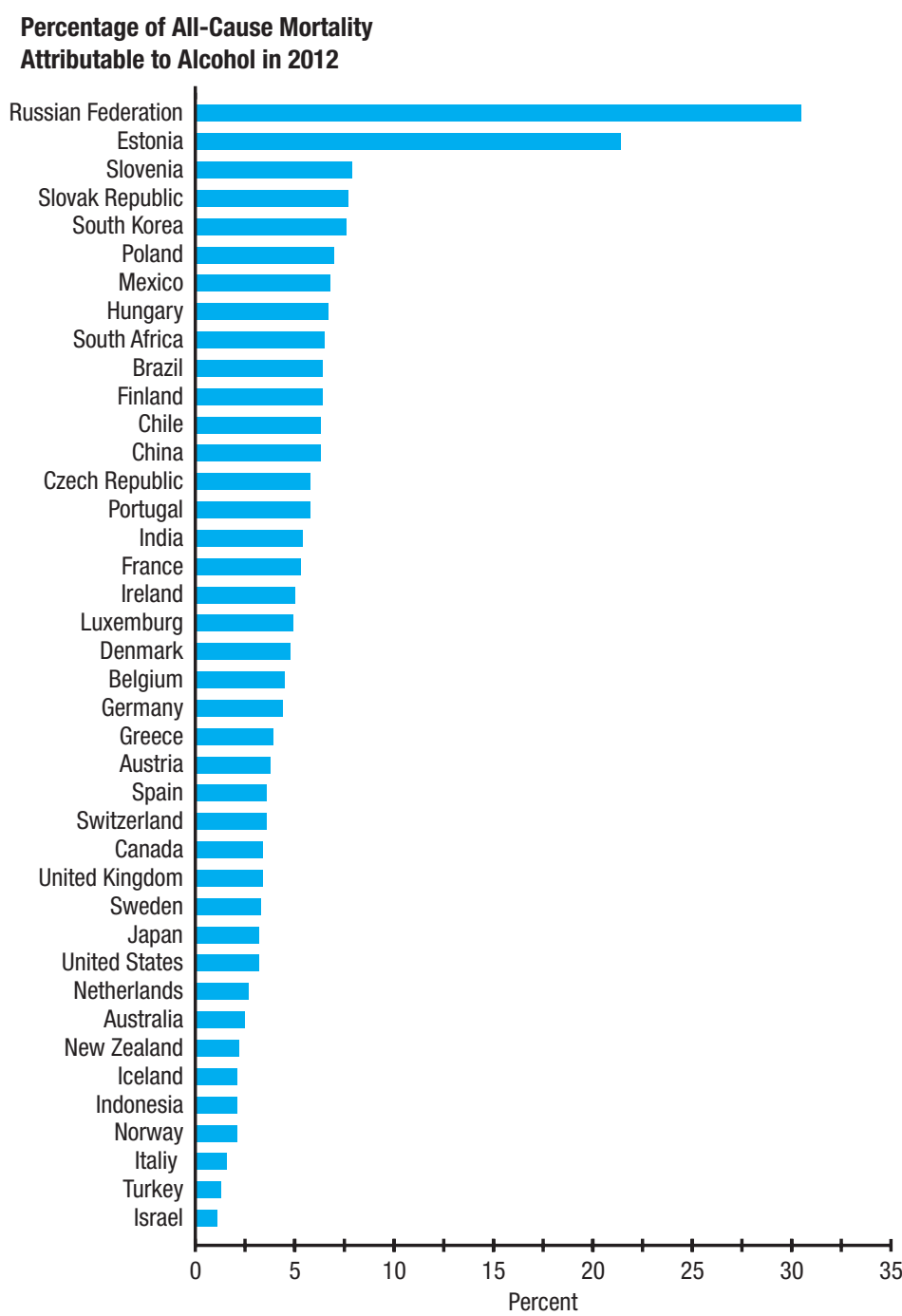

FIGURE 1.8 Percentage of all-cause mortality attributable to alcohol by country.

Source: Data from Phillips M. (2015). Russia is quite literally drinking itself to death. Retrieved from https:// qz.com/403307/russia-is-quite-literally-drinking-itself-to-death/

Providing a clear contrast, the lowest rates of alcohol use are found primarily in the Middle East and North Africa. These predominantly Islamic nations severely restrict access to alcohol. Drinking alcohol is proscribed culturally, religiously, and legally. In consequence, per capita alcohol consumption is negligible and not surprisingly, drinking alcohol contributes minimally as a determinant of health and disease in these nations.

Therefore, the causes of drinking in individuals are quite different from the causes of drinking levels in populations - a useful lesson for our understanding of health in populations that will inform our thinking in the rest of the book.

\section{SUMMARY}

Public health focuses on the health of populations. Public health has been relevant since the time when early humans transitioned to living as populations in communal settings. Public health issues that immediately came to prominence were providing the population 
with clean water and adequate nutrition while disposing of wastes. Existential challenges were posed by population encounters with common communicable diseases that caused high rates of infant and early childhood mortality, punctuated by periodic plagues that swept broad geographic regions and decimated communities.

The 20th century was marked by remarkable public health achievements that collectively accounted for more than a 25-year surge in average life expectancy. Particularly notable was the successful conquest of infectious diseases, coupled with the development and widespread distribution of vaccines; these advances had the effect of markedly decreasing childhood disease and death.

Two mass-produced human inventions, the tobacco cigarette and the automobile, generated entirely new patterns of illness and injury. Fortunately, public health interventions have been instrumental in diminishing the population burdens of smoking-attributable diseases and motor vehicle accidents.

Lifestyles changed markedly (and continue to do so), catapulting NCDs, notably cardiovascular diseases and cancers, to the forefront. The recognition of disease risk factors led to public health interventions that have successfully decreased the population burden of disability and early death from lifestyle-related diseases. Nevertheless, in the early $21 \mathrm{st}$ century, the escalating prominence of NCDs poses an ongoing challenge, and some disease trends such as obesity are visibly worsening.

Public health, powered by population health science, continues to make strides toward achieving disease prevention and health promotion. Concurrently, humans continue to demonstrate their capacity to both generate health threats (climate change is perhaps the most compelling at this moment) and to create innovative solutions. Health-enhancing endeavors are aided by the structure of the public health system, ranging from municipal health departments to state, federal, and global governmental institutions and nongovernmental programs and policies.

Access an additional case study and podcast, COVID-19 and the Susceptibility of the Human Population, online at http://connect. springerpub.com/content/book/978-0-8261-7754-4/part/part01/ chapter/ch01

COVID-19

Case and

Podcast

\section{DISCUSSION QUESTIONS}

1. Considering the list of the top 10 public health achievements for the 20 th century, and again for 2001-2010, make your predictions for the top 10 achievements that will be on the list for 2011-2020.

2. With each new era, populations encounter-and sometimes create-major threats to population health. Discuss the likely population health implications of current trends in climate change.

3. As some learners contemplate a future career in public health itself, or in public health-informed professions, discuss your preferences for working in public health at the municipal, state, federal, or international levels. 


\section{REFERENCES}

1. Rosen G. A History of Public Health. 2nd ed. Baltimore, MD: Johns Hopkins University Press; 2015.

2. Keyes KM, Galea S. Population Health Science. New York, NY: Oxford University Press; 2016. https:// global.oup.com/academic/product/population-health-science-9780190459376?cc=us\&lang=en\&

3. Barry JM. The Great Influenza: The Story of the Deadliest Pandemic in History. London: Penguin Books, Ltd.; 2004.

4. Constitution of WHO: principles. World Health Organization website. https://www.who.int/about/ mission/en

5. What is public health? CDC Foundation website. https://www.cdcfoundation.org/what-public-health

6. What is public health? American Public Health Association website. https://www.apha.org/what-is -public-health

7. Winslow C. The untilled fields of public health. Science. 1920;51(1306):23-33. doi:10.1126/science .51 .1306 .23

8. Frith J. The history of plague-part 1. The three great pandemics. J Mil Veterans Health. 2012;20(2):1116. https://jmvh.org/article/the-history-of-plague-part-1-the-three-great-pandemics

9. The 1848 Public Health Act. UK Parliament wesite. https://www.parliament.uk/about/living -heritage/transformingsociety/towncountry/towns/tyne-and-wear-case-study/about-the-group/public -administration/the-1848-public-health-act

10. Committee on Educating Public Health Professionals for the 21st Century. History and current status of public health education in the United States. In: Gebbie K, Rosenstock L, Hernandez LM, eds. Who Will Keep the Public Healthy? Washington, DC: National Academies Press; 2003:41-60. https://www.nap .edu/read/10542/chapter/5

11. Sheps CG. Higher Education for Public Health: A Report of the Milbank Memorial Fund Commission. New York, NY: Milbank Memorial Fund; 1976.

12. Centers for Disease Control and Prevention. Ten great public health achievements-United States, 1900-1999. MMWR Morb Mortal Wkly Rep. 1999;48(12):241-243. https://www.cdc.gov/mmwr/ preview/mmwrhtml/00056796.htm

13. McNeill WH. Plagues and Peoples. Port Angeles, WA: Anchor Books; 1976.

14. Surgeon General's Advisory Committee on Smoking and Health. Smoking and Health: Report of the Advisory Committee to the Surgeon General of the Public Health Service. Public Health Service Publication No. 1103. Washington, DC: Office of the Surgeon General; 1964. https://profiles.nlm.nih .gov/ps/retrieve/ResourceMetadata/NNBBMQ

15. CDC identifies 10 public health achievements of first decade of 21 st century. Centers for Disease Control and Prevention website. https://www.cdc.gov/media/releases/2011/p0519_publichealthachievements .html. Published May 19, 2011.

16. ICD-11 is here! World Health Organization website. https://www.who.int/classifications/icd/en

17. ICD-11: classifying disease to map the way we live and die. World Health Organization website. https://www.who.int/health-topics/international-classification-of-diseases. Published June 18, 2018.

18. Global burden of disease (GBD). Institute for Health Metrics and Evaluation website. http://www .healthdata.org/gbd

19. GBD compare-IHME viz hub. Institute for Health Metrics and Evaluation website. https://vizhub .healthdata.org/gbd-compare

20. Leach-Kemon K. A new way of measuring development helps assess health system performance. Institute for Health Metrics and Evaluation website. http://www.healthdata.org/acting-data/new-way-measuring -development-helps-assess-health-system-performance. Published March 28, 2017.

21. Jones DS, Podolsky SH, Greene JA. The burden of disease and the changing task of medicine. $N$ Engl J Med. 2012;366(25):2333-2338. doi:10.1056/NEJMp1113569

22. Heron M. Deaths: leading causes for 2016. Natl Vital Stat Rep. 2018;67(6):1-77. https://www.cdc .gov/nchs/data/nvsr/nvsr67/nvsr67_06.pdf

23. The top 10 causes of death. World Health Organization website. https://www.who.int/news-room/fact -sheets/detail/the-top-10-causes-of-death. Published May 24, 2018.

24. World Bank country and lending groups. The World Bank website. https://datahelpdesk.worldbank.org/ knowledgebase/articles/906519-world-bank-country-and-lending-groups

25. About HHS. U.S. Department of Health \& Human Services website. https://www.hhs.gov/about/index .html

26. HHS Secretary. U.S. Department of Health \& Human Services website. https://www.hhs.gov/about/ leadership/secretary/index.html. Published 2019.

27. Office of the Surgeon General. U.S. Department of Health \& Human Services website. https://www .surgeongeneral.gov 
28. HHS Office of the Assistant Secretary for Preparedness and Response. Public Health Emergency website. https://www.phe.gov/ABOUT/ASPR/Pages/default.aspx. Published 2019.

29. Centers for Disease Control and Prevention. CDC website. https://www.cdc.gov

30. National Institutes of Health. NIH website. https://www.nih.gov

31. U.S. Food and Drug Administration. FDA website. https://www.fda.gov

32. The U.S. Centers for Medicare \& Medicaid Services. CMS website. https://www.cms.gov

33. Substance Abuse and Mental Health Services Administration. SAMHSA website. https://www.samhsa gov

34. Indian Health Service (IHS). IHS website. https://www.ihs.gov

35. World Health Organization. WHO website. https://www.who.int

36. UN Women. UN Women website. http://www.unwomen.org/en

37. UNAIDS. UNAIDS website. http://www.unaids.org/en

38. United Nations Office on Drugs and Crime. UNODC website. http://www.unodc.org

39. The UN Refugee Agency. UNHCR website. https://www.unhcr.org

40. United Nations Relief and Works Agency for Palestine Refugees. UNRWA website. https://www.unrwa.org

41. UNICEF for every child. UNICEF website. https://www.unicef.org

42. World Food Programme. WFP website. https://www1.wfp.org

43. Pan American Health Organization. PAHO website. https://www.paho.org/hq/index.php?lang=en

44. American Cancer Society. American Cancer Society website. https://www.cancer.org

45. Dutch Cancer Society. Dutch Cancer Society website. https://www.kwf.nl/english/Pages/The -organisation.aspx

46. Saudi Cancer Society. Saudi Cancer Society website. http://saudicancer.org

47. Susan G. Komen Breast Cancer Foundation. Susan G. Komen website. https://ww5.komen.org

48. Acoustic Neuroma Association. ANA website. https://www.anausa.org

49. American Heart Association. AHA website. https://www.heart.org

50. American Lung Association. ALA website. https://www.lung.org

51. American Diabetes Association. ADA website. http://www.diabetes.org

52. Alzheimer's Foundation of America. AFA website. https://alzfdn.org

53. Mothers Against Drunk Driving. MADD website. https://www.madd.org

54. Sandy Hook Promise. Sandy Hook Promise website. https://www.sandyhookpromise.org

55. Hope after suicide. Alliance of Hope website. https://allianceofhope.org

56. American Public Health Association. APHA website. https://www.apha.org

57. American Medical Association. AMA website. https://www.ama-assn.org

58. American Psychiatric Association. APA website. https://www.psychiatry.org

59. Academy of Consultation-Liaison Psychiatry. ACLP website. https://www.clpsychiatry.org

60. Informing humanitarians worldwide. Reliefweb website. https://reliefweb.int

61. American Red Cross. Red Cross website. https://www.redcross.org

62. International Federation of Red Cross and Red Crescent Societies. IFRC website. https://media.ifrc.org/ifrc

63. CARE. CARE website. https://www.care.org

64. Caritas. Caritas website. https://www.caritas.org

65. Doctors Without Borders (Médecins Sans Frontières) International. MSF website. https://www.msf.org

66. Catholic Charities USA. Catholic Charities USA website. https://www.catholiccharitiesusa.org

67. Episcopal Relief \& Development. Episcopal Relief \& Development website. https://www.episcopalrelief.org

68. Lutheran World Relief. LWR website. https://lwr.org

69. Mennonite Central Committee. MCC website. https://mcc.org

70. Results from the 2015 National Survey on Drug Use and Health: detailed tables. Substance Abuse and Mental Health Services Administration website. https://www.samhsa.gov/data/sites/default/files/ NSDUH-DetTabs-2015/NSDUH-DetTabs-2015/NSDUH-DetTabs-2015.htm\#tab2-41b

71. Underage drinking. National Institute on Alcohol Abuse and Alcoholism website. https://pubs.niaaa.nih .gov/publications/UnderageDrinking/UnderageFact.htm

72. Young R, Macdonald L, Ellaway A. Associations between proximity and density of local alcohol outlets and alcohol use among Scottish adolescents. Health Place. 2013;19(100):124-130. doi:10.1016/ j.healthplace.2012.10.004

73. Pereira G, Wood L, Foster S, Haggar F. Access to alcohol outlets, alcohol consumption and mental health. PLoS One. 2013;8(1):e53461. doi:10.1371/journal.pone.0053461

74. Campbell CA, Hahn RA, Elder R, et al. The effectiveness of limiting alcohol outlet density as a means of reducing excessive alcohol consumption and alcohol-related harms. Am J Prev Med. 2009;37(6): 556-569. doi:10.1016/j.amepre.2009.09.028

75. Livingston M, Chikritzhs T, Room R. Changing the density of alcohol outlets to reduce alcohol-related problems. Drug Alcohol Rev. 2007;26(5):557-566. doi:10.1080/09595230701499191 


\section{CHAPTER 1 CASE STUDY: COVID-19 AND THE SUSCEPTIBILITY OF THE HUMAN POPULATION}

Coronavirus disease 2019 (COVID-19) was initially detected in Wuhan, the capital city of the landlocked province of Hubei, China, in late 2019. ${ }^{1}$ The first cases of "pneumonia of unknown cause" were reported to the World Health Organization (WHO) Country Office in China on December 31, 2019. SARS-CoV-2, the coronavirus that causes COVID-19 and a relative of the viruses that cause severe acute respiratory syndrome (SARS) and Middle East respiratory syndrome, was quickly isolated. Within weeks, its genetic sequence was deciphered.

COVID-19 spread throughout Hubei and across mainland China and began moving into neighboring Western Pacific Region nations with such breathtaking speed that the WHO declared the outbreak to be a Public Health Emergency of International Concern just 1 month later, on January 30, 2020. ${ }^{2}$ Although known for just 2 months, COVID-19 had already become a population phenomenon, with 7,818 confirmed cases on that day.

In the early months of 2020, earth's 7.8 billion human inhabitants all shared one characteristic - susceptibility to infection and illness. The entire global population was immunologically naïve to this novel virus. Moreover, the infectious agent, SARS-CoV-2, had the constellation of the key attributes to make COVID-19 a worldwide scourge: high infectivity, high pathogenicity, and high virulence. SARS-CoV-2 could infect persons with relative ease (infectivity); produce diagnosable disease in a high proportion of those infected (pathogenicity), and progress to severe or fatal disease in a substantial subset (virulence). In the early months, the global proportion of confirmed cases of COVID-19 who died was over $6 \%$ and rising.

During the month of March 2020, the COVID-19 outbreak exploded, wrapping completely around the globe, surging throughout the European continent, and invading the Americas. ${ }^{3}$ On March 11, 2020, the WHO officially pronounced COVID-19 to be a pandemic. ${ }^{4}$ By the end of that month, the United States had surpassed China and Italy to become the nation with the highest number of cases, and several weeks into April 2020, the United States had more deaths than any other country. By the 7-month mark, the Americas - the entire Western Hemisphere-was dominating the global case counts and the United States alone was contributing almost one-quarter of all cases (Figure 1.1). ${ }^{5}$

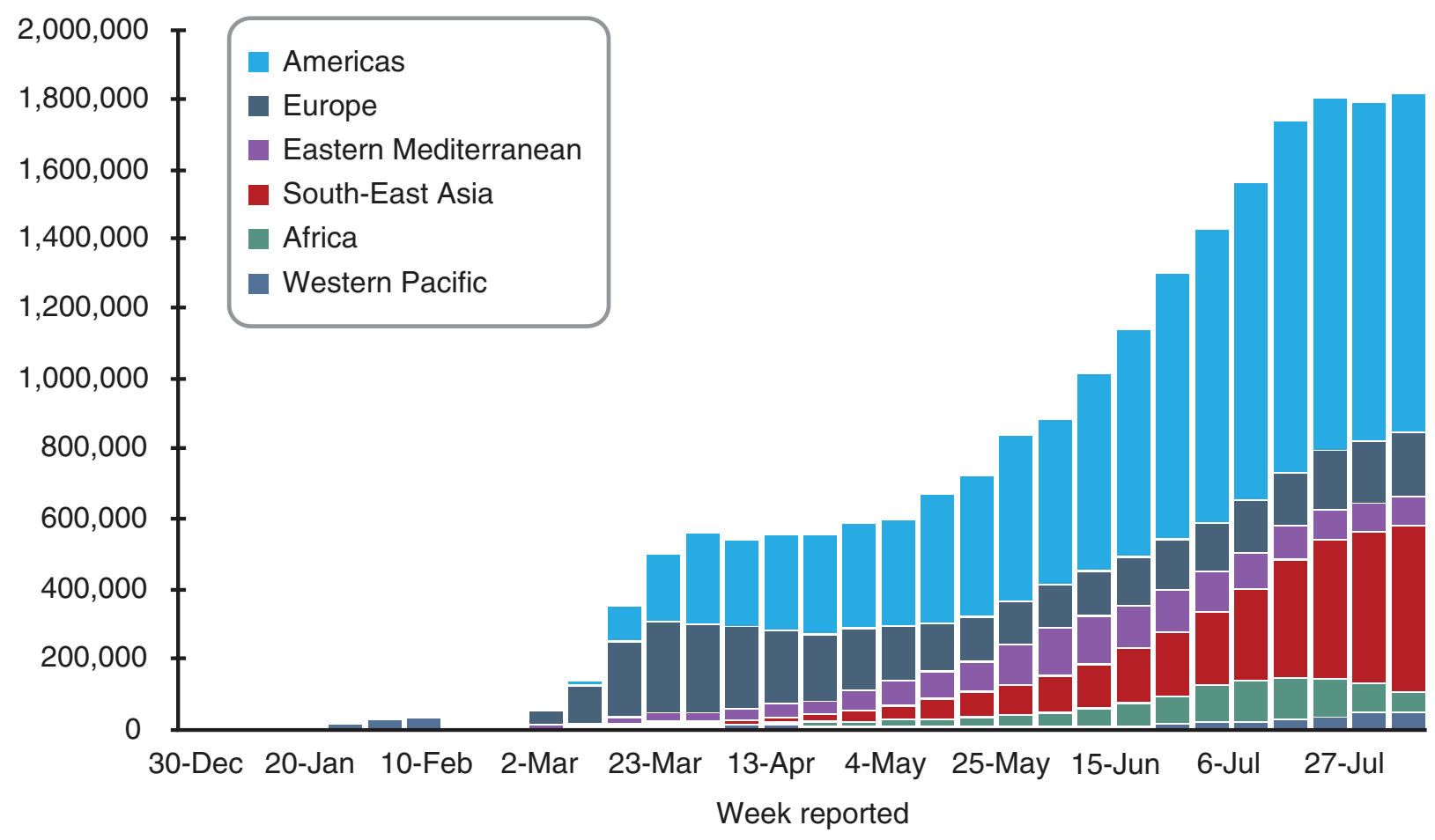

FIGURE 1.1 Number of COVID-19 cases reported weekly by WHO region (December 30, 2020 to August 16, 2020). WHO, World Health Organization.

Source: World Health Organization. Coronavirus disease 2019 (COVID-19) Situation Report 180. July 18, 2020. https://www.who.int/docs/defaultsource/coronaviruse/situation-reports/20200718-covid-19-sitrep-180.pdf?sfursn=39b31718_2 
A population is frequently defined as people in a particular place, typically demarcated by discernible geopolitical boundaries. In terms of COVID-19, most nations or territories worldwide were reporting confirmed cases to the WHO; within the first quarter of 2020, the tally of these geopolitical entities notifying the WHO exceeded 200. Within each nation, subdivisions-states, provinces, and prefectures-and municipalities were tracking COVID-19 cases and attempting to implement measures to slow the spread.

A population is also defined as a set of shared characteristics. In terms of COVID-19, perhaps the most universal of these commonalities is susceptibility to infection and illness. Each individual-each world citizen - can potentially be infected with SARS-CoV-2. Many of the individuals who are infected with the virus will become infectious to others at some point, even those infected individuals who remain asymptomatic and do not show signs of illness. Many others, perhaps most of the infected individuals, will develop symptoms ranging from mild to severe, and some will die. Moreover, regardless of whether a person becomes infected or develops illness, all persons are vulnerable to the cascading health consequences that COVID-19 sets in motion.

Population health science is the study of the conditions that shape distributions of health within and across populations. During 2020, the COVID-19 pandemic was radically reshaping distributions of health and disease worldwide, dominating the delivery of healthcare, and derailing or sidelining the provision of care-preventive and therapeutic - for all other conditions. In a matter of several months, COVID-19 was transforming the mechanisms through which these conditions manifest as the health of individuals.

Population health science provides us with the science and tells us what we need to know to understand what it is that causes health, so that then, in public health, we can intervene to make populations better. Fortunately, past successes provide guidance here and some optimism.

Although the 1900s included the extraordinary exclamation point of the 1918-1919 great influenza pandemic, during the 20th century, life expectancy in the United States increased by almost 30 years on average. The Centers for Disease Control and Prevention attributes most of that gain in longevity -25 years - to the 10 great public health achievements of the 20th century. ${ }^{6}$ Among the most powerful contributors to longer, healthier life were two interrelated achievements, vaccination and control of infectious diseases that are urgently applicable in the age of COVID-19.

Unlike the 1918-1919 influenza pandemic that killed an estimated 50 million persons over a sequence of three waves, ${ }^{7}$ we now know what a virus is, how to visualize and gene-sequence a novel virus, and ultimately how to develop lifesaving vaccines. Vaccination has proven effective in ridding the world of smallpox, banishing poliomyelitis from all but a handful of nations, and controlling the spread of measles, diphtheria, rubella, and tetanus.

The prospect of developing an effective vaccine extends a lifeline to our populous planet as COVID-19 is circulating worldwide. Despite living at a time when earth has five times more inhabitants and global interconnectedness disseminates virus across oceans and spreads virus around continents in the blink of an eye, we have the hope of rapid development of a vaccine.

The entire human population is susceptible to infection with SARS-CoV-2, which appears to be more transmissible than the great influenza of 1918/1919. ${ }^{7}$ However, a vaccine, if developed in a timely manner, may spare us from the escalating mass mortality that ravaged the planet a century ago. No longer ignorant of viral spread, we are equipped to test, identify cases, conduct contact tracing, and selectively quarantine potential spreaders. This is a stopgap, harm-reduction approach to slow transmission, but not ultimately a solution in itself.

This pre-vaccine interval of abject susceptibility is a precarious time when we are largely reliant on blunt force mitigation and suppression measures like lockdowns, physical distancing, and personal hygiene. ${ }^{8}$ These are imperfect measures that must be maintained for prolonged durations. They are difficult to enforce in free-living populations that concurrently experience cascading economic and social repercussions.

By midsummer 2020, strict mitigation measures had been employed with considerable success throughout much of the Western Pacific and across all nations comprising the European Union..$^{9,10}$ Case counts had diminished to numbers small enough to employ the stalwarts of infectious disease containment: surveillance, case identification, isolation of cases, contact tracing, and quarantine of contacts. In these regions, mitigation measures appear able to limit viral spread and hold COVID-19 at bay long enough to immunize the population when a vaccine becomes available, and potentially spare millions of lives. Unfortunately, this is not the situation throughout the Americas. In particular, the United States and Brazil did not apply measures of sufficient stringency and duration to diminish cases to a point where community spread was controlled. In those nations, marked by rapid and premature reopening, cases were resurging dramatically throughout the summer of 2020, sparking widespread illness and massive preventable loss of life. 


\section{REFERENCES}

1. Morens DM, Daszak P, Taubenberger JK. Escaping Pandora’s box — another novel coronavirus. New Engl J Med. 2020;382:1293-1295. https://doi.org/10.1056/NEJMp2002106

2. World Health Organization. Statement on the second meeting of the International Health Regulations (2005) Emergency Committee regarding the outbreak of novel coronavirus (2019-nCoV). January 30, 2020. https://www.who.int/news-room/detail/30-01-2020statement-on-the-second-meeting-of-the-international-health-regulations-(2005)-emergency-committee-regarding-the-outbreak-of-novelcoronavirus-(2019-ncov)

3. Shultz JM, Perlin A, Saltzman RG, et al. Pandemic March: 2019 coronavirus disease's first wave circumnavigates the globe. Disaster Med Public Health Prep. 2020;14;e28-e32. https://doi.org/10.1017/dmp.2020.103

4. World Health Organization. WHO Director-General's opening remarks at the media briefing on COVID-19 - 11 March 2020. March 11, 2020. https://www.who.int/dg/speeches/detail/who-director-general-s-opening-remarks-at-the-media-briefing-on-covid-19---11march-2020

5. World Health Organization. Coronavirus disease 2019 (COVID-19) Situation Report 180. July 18, 2020. https://www.who.int/docs/ default-source/coronaviruse/situation-reports/20200718-covid-19-sitrep-180.pdf?sfvrsn=39b31718_2

6. Centers for Disease Control and Prevention. Ten great public health achievements-United States, 1900-1999. MMWR Morb Mortal Wkly Rep. 1999;48(12):241-243. https://pubmed.ncbi.nlm.nih.gov/10220250

7. Barry JM. The Great Influenza: The story of the deadliest plague in history. Penguin Group; 2004.

8. Ferguson NM, Laydon D, Nedjati-Gilani G, et al. Impact of non-pharmaceutical interventions (NPIs) to reduce COVID-19 mortality and healthcare demand (Report 9). WHO Collaborating Centre for Infectious Disease Modelling MRC Centre for Global Infectious Disease Analysis, Imperial College London; March 16, 2020. https://www.imperial.ac.uk/mrc-global-infectious-disease-analysis/covid19/report-9-impact-of-npis-on-covid-19

9. Hsiang S, Allen D, Annan-Phan S, et al. The effect of large-scale anti-contagion policies on the COVID-19 pandemic. Nature. 2020;584(7820):262-267. https://doi.org/10.1038/s41586-020-2404-8.

10. Flaxman S, Mishra S, Gandy A, et al. Estimating the effects of non-pharmaceutical interventions on COVID-19 in Europe. Nature. 2020;584(7820):257-261. https://doi.org/10.1038/s41586-020-2405-7 